\title{
NT-proBNP as a marker of postoperative heart failure in adult cardiac surgery
}

Huiqi Jiang

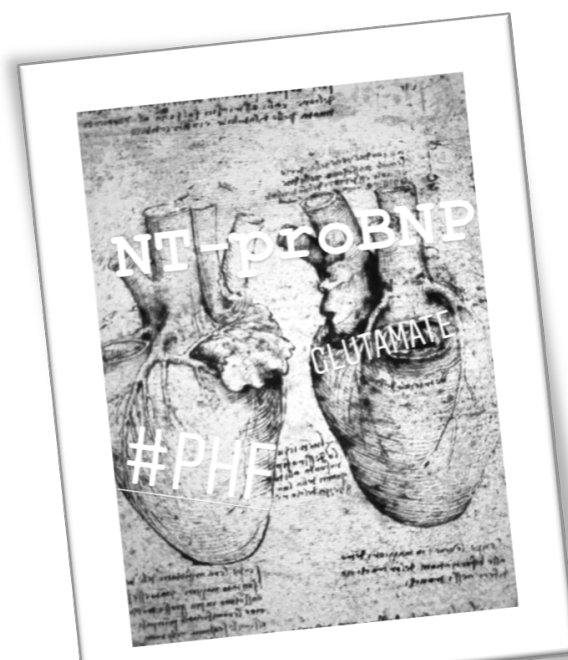




\title{
NT-proBNP as a marker of postoperative heart failure in adult cardiac surgery
}

\author{
Huiqi Jiang
}

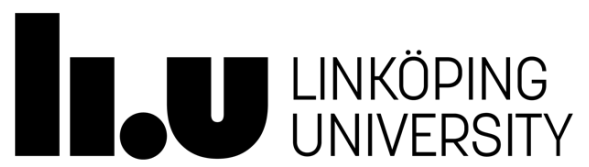

Department of Medical and Health Sciences

Linköping University, Sweden

Linköping 2019 
(C)Huiqi Jiang, 2019

Cover design: Leonardo \& Rolf

Published articles have been reprinted with the permission of the copyright holder.

Printed in Sweden by LiU-Tryck, Linköping, Sweden, 2019

ISBN 978-91-7929-969-9

ISSN $0345-0082$ 
To Shujin, Zilin and Xuelin

"Learn avidly. Question it repeatedly. Analyze it carefully. Then put what you have learned into practice intelligently."

Confucius 



\section{CONTENTS}

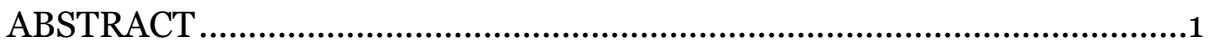

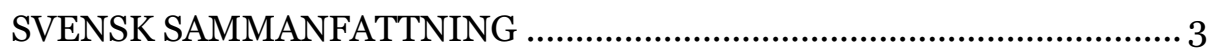

LIST OF PAPERS ………………….......................................................... 5

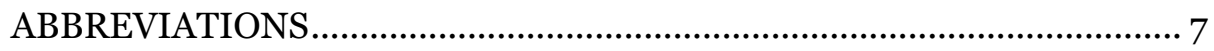

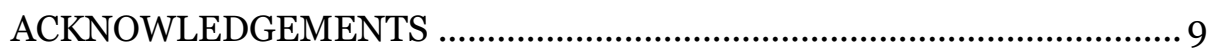

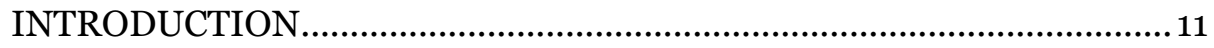

Postoperative heart failure..................................................................... 11

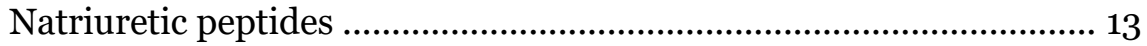

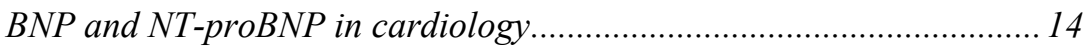

Preoperative BNP and NT-proBNP in cardiac surgery......................... 15

Postoperative BNP and NT-proBNP in cardiac surgery ....................... 17

Treatment of postoperative heart failure ............................................... 18

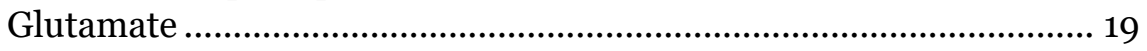

AIMS OF THE DISSERTATION ……................................................... 21

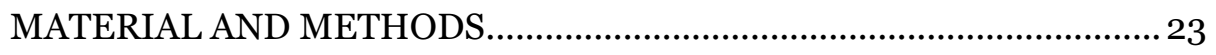

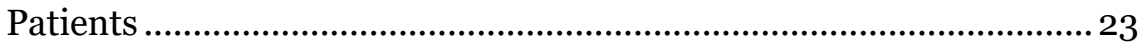

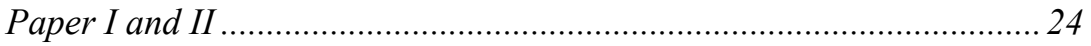

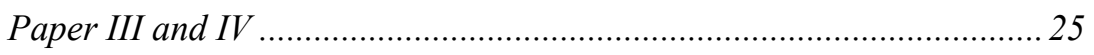

Clinical management............................................................................ 26

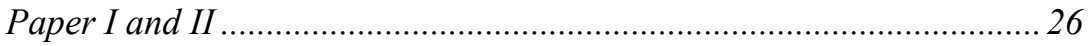

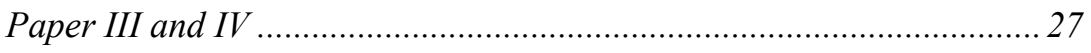

Surgical pulmonary artery catheter ................................................... 28

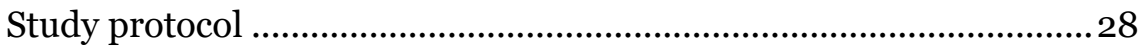

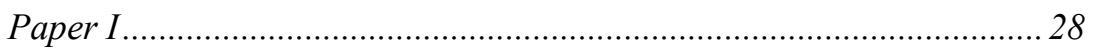

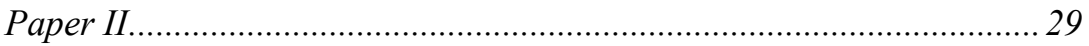

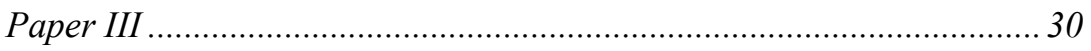

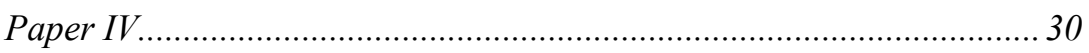

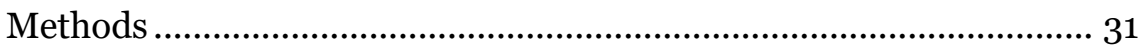




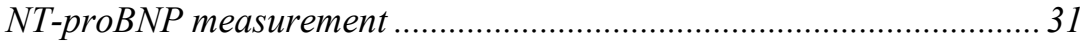

Mixed venous oxygen saturation $\left(\mathrm{SvO}_{2}\right)$ measurement ............................32

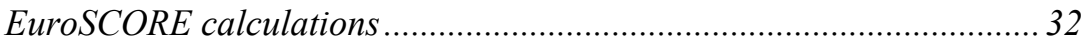

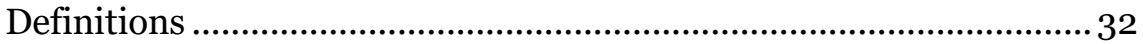

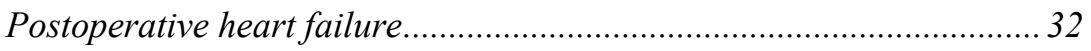

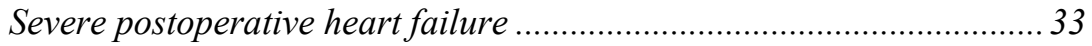

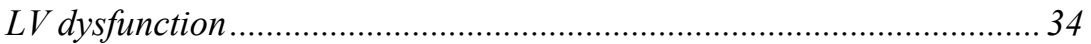

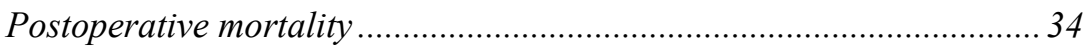

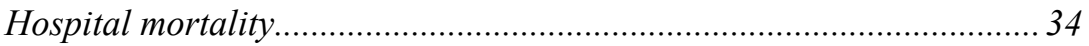

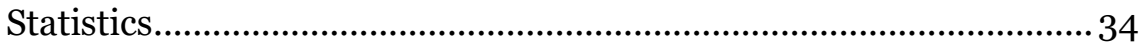

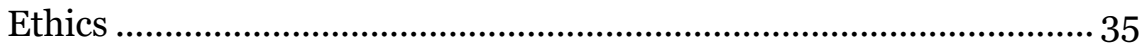

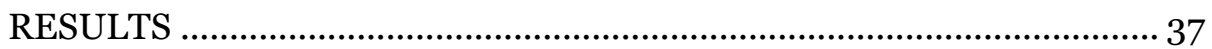

Preoperative NT-proBNP and underlying heart disease (Paper I)..... 37

Preoperative NT-proBNP and severe postoperative heart failure

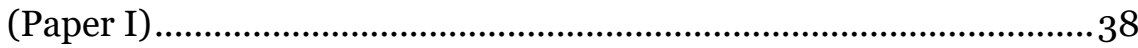

Preoperative NT-proBNP and postoperative mortality (Paper I) .......39

NT-proBNP levels in relation to PHF in surgery for aortic stenosis

(Paper II)

NT-proBNP and PHF related to long-term survival after surgery for aortic stenosis (Paper II).......................................................................... 43

PHF and severe PHF in isolated CABG for ACS (Paper III) ................. 46 Postoperative NT-proBNP in relation to PHF in isolated CABG for ACS (Paper III)

Postoperative changes of NT-proBNP in relation to PHF in isolated

CABG for ACS (Paper III)

Postoperative NT-proBNP in relation to severe PHF in isolated CABG for ACS (Paper III)

Influence of glutamate on postoperative NT-proBNP in patients undergoing CABG for ACS (Paper IV) ................................................... 52 Influence of glutamate on postoperative NT-proBNP in high risk patients undergoing CABG for ACS (Paper IV).................................... 53

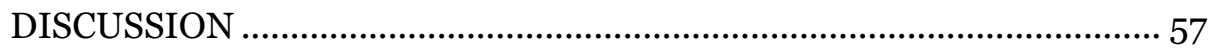

PHF after cardiac surgery …………………….................................. 57

NT-proBNP in cardiac surgery ……………………............................ 59

The impact of underlying heart disease on preoperative NT-proBNP ... 59

Preoperative NT-proBNP in cardiac surgery ........................................ 60

Postoperative NT-proBNP and postoperative heart failure .................... 62 
The impact of glutamate on postoperative NT-proBNP 64

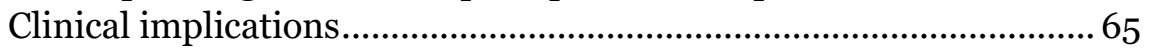

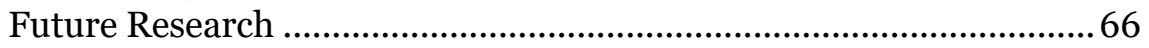

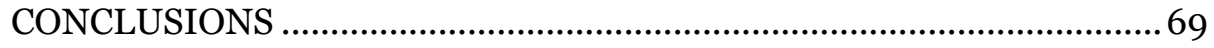

REFERENCES …............................................................................... 


\section{ABSTRACT}

Postoperative heart failure (PHF) remains the major cause of mortality after cardiac surgery. Unfortunately, generally accepted diagnostic criteria for PHF are lacking. This may explain why the evidence for the efficacy and safety of current treatment of PHF with inotropes is insufficient. In cardiology practice N-terminal pro-B-type natriuretic peptide (NT-proBNP) is an established biomarker for heart failure. However, the association between NT-proBNP and PHF after cardiac surgery needs further clarification. Glutamate is a key intermediate in myocardial metabolism, which may improve myocardial tolerance to ischemia and facilitate post-ischemic recovery. Glutamate was associated with a reduced risk of developing severe $\mathrm{PHF}$ in high-risk patients undergoing coronary artery bypass surgery (CABG). The aim of this thesis was to study the role of NT-proBNP for prediction and assessment of PHF in cardiac surgery (Paper I-III) and the impact of intravenous glutamate infusion on postoperative NT-proBNP after CABG (Paper IV).

Paper I: We retrospectively studied the role of underlying heart disease for preoperative NT-proBNP in patients admitted for first time CABG $(n=2226)$, aortic valve surgery (AVR) for aortic stenosis (AS) $(n=406)$ and mitral valve surgery for mitral valve regurgitation (MR) $(n=346)$ by adjusting for non-cardiac confounders (age, gender, obesity and renal function). The level of NT-proBNP in AS or MR was 1.67 ( $\mathrm{p}<0.0001)$ and 1.41 times $(\mathrm{p}<0.0001)$ higher respectively than in coronary artery disease (CAD) after adjusting for confounders. Preoperative NT-proBNP was predictive of severe $\mathrm{PHF}$ in $\mathrm{CAD}$ and $\mathrm{MR}$ patients but less so in $\mathrm{AS}$ patients. Preoperative NT-proBNP emerged as an independent risk factor for severe PHF and postoperative mortality in $\mathrm{CAD}$ patients.

Paper II-III: We prospectively studied the association between postoperative NT-proBNP and PHF in two cohorts, patients undergoing AVR for AS 
$(n=203)$ and patients undergoing isolated CABG for acute coronary syndrome (ACS) from the GLUTAMICS-trial $(n=382)$. NT-proBNP was measured preoperatively, on the first (POD1) and third postoperative morning (POD3). An end-points committee blinded to NT-proBNP used prespecified criteria to diagnose PHF and its severity. After AVR for AS only NTproBNP level on POD1 provided good discrimination of PHF. PHF with NT-proBNP POD1 $\geq 5290 \mathrm{ng} \cdot \mathrm{L}^{-1}$ emerged as an independent risk factor for long-term mortality (Paper II). After isolated CABG for ACS both absolute postoperative levels on POD1 and POD3 and postoperative increases of NTproBNP were associated with PHF and the levels reflected the severity of PHF (Paper III).

Paper IV: We prospectively studied the impact of intravenous glutamate infusion on postoperative NT-proBNP in a randomized double-blind study on patients undergoing CABG for ACS from the GLUTAMICS-trial $(n=399)$. Patients were randomly allocated to intravenous infusion of Lglutamate $(n=200)$ or saline $(n=199)$. No effect of glutamate on postoperative NT-proBNP levels was detected in the whole cohort. According to post-hoc analysis glutamate was associated with less increase of NTproBNP from preoperative level to POD3 and significantly lower absolute levels on POD3 among high risk patients with EuroSCORE II $\geq 4.15$ (upper quartile).

Conclusion: Patients with AS or MR have higher preoperative NTproBNP than CAD patients after adjusting for confounders. The predictive value of NT-proBNP with regard to severe PHF and postoperative mortality was confirmed in CAD patients. Postoperative NT-proBNP may prove a useful tool for assessment of PHF after AVR for AS and isolated CABG. NTproBNP POD1 identifies patients with $\mathrm{PHF}$ at risk of a poor long-term survival after AVR for AS. Intravenous infusion of glutamate may prevent or mitigate PHF in high-risk patients undergoing CABG but these results need to be confirmed. 


\section{SVENSK SAMMANFATTNING}

Hjärtkirurgi kan idag utföras med mycket goda resultat. Hjärtsvikt kvarstår dock som en viktig komplikation och svarar för flertalet dödsfall i samband med operation. Mot denna bakgrund är det olyckligt att det idag saknas allmänt accepterade kriterier för hur hjärtsvikt efter hjärtoperation ska diagnosticeras. Det är en bidragande orsak till att det fortfarande saknas tillfredställande vetenskapligt underlag för den behandling som ges. Traditionell behandling innebär att man ger inotropa (hjärtstärkande) läkemedel som ökar hjärtminutvolymen men som samtidigt ökar hjärtats syrebehov kraftigt. Eftersom flertalet fall av hjärtsvikt efter kranskärlsoperation orsakas av syrebrist riskerar detta att förvärra en bakomliggande hjärtinfarkt. Det finns studier som talar för att liberal användning av dessa läkemedel är skadliga för patienterna.

NT-proBNP är en etablerad markör för hjärtsvikt inom kardiologin men har inte fått samma genomslag i hjärtkirurgisk verksamhet. Målsättningen med detta avhandlingsarbete var att utvärdera hur NT-proBNP påverkas av bakomliggande hjärtsjukdom och om NT-proBNP kan användas för att värdera hjärtsvikt efter operation. Glutamat är en aminosyra som har en nyckelroll i hjärtats ämnesomsättning med potential att kunna underlätta hjärtats återhämtning efter syrebrist. Vi har därför också studerat om intravenös glutamatinfusion påverkar nivåerna av NT-proBNP efter operation.

NT-proBNP nivåerna i blod stiger när hjärtat utsätt för tryck eller volymsbelastning men även syrebrist bidrar i oklar omfattning till förhöjda nivåer. Avhandlingsarbetet visar att patienter som kommer till operation pga förträngning av aortaklaffen och läckage av mitralisklaffen har klart högre nivåer av NT-proBNP före operation jämfört med kranskärlssjuka patienter. Detta gäller även när man justerar för faktorer som ålder, kön, övervikt och njurfunktion som kan påverka NT-proBNP nivåerna. Resultaten talar för att tryck och volymsbelastning är av större betydelse för NT-proBNP nivåerna än syrebrist.

I likhet med tidigare studier fann vi att hjärtsvikt efter kranskärlsoperation var förenad med hög tidig dödlighet medan tillståndet föreföll ganska lindrigt till en början hos dem som opererades för aortaklaff-förträngning. De allvarliga konsekvenserna i form av en kraftigt ökad dödlighet under uppföljningstiden blev uppenbara först efter några år.

NT-proBNP nivåerna efter operation studerades hos patienter som opererades för aortaklaff-förträngning och kranskärlssjukdom. Nivåerna steg 
betydligt mer efter operation hos dem som drabbades av hjärtsvikt. I kranskärlsgruppen graderades svårighetsgraden av hjärtsvikt och nivåerna föreföll då reflektera svårighetsgraden. Hos patienter som opererade för aortaklaff-förträngning var det bara proverna den första dagen efter operation som tydligt var kopplade till hjärtsvikt. Dessa prover kunde dock identifiera vilka patienter med hjärtsvikt det var som löpte en kraftigt ökad risk att avlida de närmaste åren och därför var i behov av ökad uppmärksamhet under uppföljningstiden.

I en avslutande studie fann vi att intravenös glutamatinfusion inte påverkade de genomsnittliga nivåerna av NT-proBNP hos merparten av patienter som kranskärlsopererades. Däremot visade en post hoc-analys att den fjärdedel av patienterna som bedömdes ha högst operationsrisk hade signifikant lägre stegring av NT-proBNP och därmed även lägre nivåer av NTproBNP efter operation.

Sammantaget har studierna bidragit till ökad kunskap om NT-proBNP i de tre största patientgrupperna som behöver hjärtopereras och de har bekräftat värdet av NT-proBNP som riskmarkör före operation.

Studierna talar för att NT-proBNP efter operation kan användas som markör för hjärtsvikt vilket skulle kunna vara av särskild betydelse för framtida studier där man utvärderar ny behandling för hjärtsvikt efter hjärtkirurgi.

Studierna talar för att NT-proBNP kan identifiera vilka patienter som behöver skärpta kontroller för att de löper ökad risk för förtida död med anledning av att de haft hjärtsvikt vid operation för aortaklaff-förträngning.

Slutligen talar NT-proBNP analyser för att intravenös glutamatinfusion minskar risken för hjärtsvikt efter kranskärlsoperation hos patienter med ökad operationsrisk. Dessa resultat behöver dock bekräftas i nya studier innan glutamat kan rekommenderas för allmänt kliniskt bruk. 


\section{LIST OF PAPERS}

I. Impact of underlying heart disease per se on the utility of preoperative NT-proBNP in adult cardiac surgery.

Jiang H, Hultkvist H, Holm J, Vánky F, Yang Y, Svedjeholm R. PloS ONE 13(2): e0192503.

II. NT-proBNP and postoperative heart failure in surgery for aortic stenosis.

Jiang H, Vánky F, Hultkvist H, Holm J, Yang Y, Svedjeholm R. Open Heart 2019 :eoo1063.

III. NT-proBNP for assessment of postoperative heart failure after coronary artery bypass surgery.

Jiang H, Holm J, Vidlund M, Vánky F, Friberg Ö, Yang Y, Svedjeholm R.

Submitted

IV. The impact of glutamate infusion on postoperative NT-proBNP in patients undergoing coronary artery bypass surgery.

Jiang H, Holm J, Vidlund M, Vánky F, Friberg Ö, Yang Y, Svedjeholm R.

Manuscript 
List of Papers

6 


\section{ABBREVIATIONS}

ACS

AMI

AS

AUC

AVR

BMI

BNP

BW

CABG

CAD

CCS

CI

CK-MB

COPD

CPB

$\mathrm{CV}$

ESC

EuroSCORE

eGFR

GCP

GIK

GLUTAMICS

HR

ICU

LV

LVEF

MR

NAD

NT-proBNP

NYHA

OR

PHF

POD1

POD3
Acute coronary syndrome

Acute myocardial infarction

Aortic stenosis

Area under the curve

Aortic valve replacement

Body mass index

B-type natriuretic peptide

Body weight

Coronary artery bypass surgery

Coronary artery disease

Canadian Cardiovascular Society

Confidence Interval

Creatine kinase-MB isoenzyme

Chronic obstructive pulmonary disease

Cardiopulmonary bypass

Coefficient of variation

European Society of Cardiology

European system for cardiac operative risk evaluation score

estimated glomerular filtration rate according to MDRD formula

Good Clinical Practice

glucose-insulin-potassium

GLUTAmate for Metabolic Intervention in

Coronary Surgery trial

Hazard Ratio

Intensive care unit

Left ventricular

Left ventricular ejection fraction

Mitral valve regurgitation

Nicotinamide adenine dinucleotide

$\mathrm{N}$-terminal pro-B-type natriuretic peptide

New York Heart Association

Odds Ratio

Postoperative heart failure

Postoperative day 1 (first postoperative morning)

Postoperastive day 3 (third postoperative morning) 
PREEV

PREOP

ROC

SAP

$\mathrm{SvO}_{2}$

TAVI

URL
Preoperative evaluation

Preoperative (the day before the index procedure)

Receiver Operating Characteristic analysis

Systolic arterial pressure

Mixed venous oxygen saturation

Transcatheter aortic valve implantation

Upper reference limit 


\section{ACKNOWLEDGEMENTS}

The work in this dissertation was carried out at the Departments of Cardiothoracic Surgery and Anesthesia, Linköping University Hospital. Papers III and IV were done in collaboration with the Departments of Cardiothoracic Surgery and Anesthesia of Örebro University Hospital and Blekinge County Hospital, Karlskrona.

Financial support was received from The Swedish Heart-Lung Foundation, Lions Research Foundation, Capio Research Foundation, ALF grants from County Council of Östergötland and Linkoping University, Sweden.

I would like to express my sincere gratitude to everyone who helped me and contributed to the completion of this dissertation. I especially want to thank:

Rolf Svedjeholm, my principal supervisor. For your patience while guiding me through these works. For showing me what is scientific research. For your abundant knowledge and outstanding logical reasoning. For interesting and important discussions. For help with the Swedish abstract. For your kindness and humor. It was my pleasure to work with you.

Yanqi Yang, my co-supervisor and head of Department of Cardiothoracic Surgery, Sun Yat-Sen Memorial Hospital in Guangdong China. For introducing me to become a PhD student at Linköping University. For your enthusiasm on scientific research and your very constructive discussions on the studies.

Jonas Holm, my co-supervisor. For your valuable input to all my work during these years. 
Farkas Vánky, my co-supervisor. For constructive criticism and inspiring scientific discussions.

Henrik Hultkvist, Mårten Vidlund, Örjan Friberg for your important contribution as co-authors.

Mats Fredrikson. For statistical advice when needed.

Thank you, Kajsa Bendtsen and Maj-Britt Tornell for the help with this project.

Eva Ahlgren Andersson, Head of the Department of Cardiothoracic and Vascular Surgery. For allowing me to pursue the scientific path and facilitating my research project.

All the colleagues at the Department of Cardiothoracic and Vascular surgery and Cardiothoracic Anesthesia for being good friends and part of a good working climate.

Gabriella Boano, Ulf Hermansson, Heli Venhoranta and Jacek Baranowski. For intersting discussions, support and enthusiasm.

My parents, Bingtian and Lian, and my parents in law, Naichang and Shixiang, for always being there.

Shujin, Zilin and Xuelin, my beloved husband and children. 


\section{INTRODUCTION}

\section{Postoperative heart failure}

Postoperative heart failure (PHF) or low cardiac output syndrome remains the major cause of mortality after cardiac surgery ${ }^{1-6}$. PHF after coronary artery bypass surgery (CABG), which is reported to occur in $3 \%$ to $14 \%$ of the cases, typically presents at weaning from cardiopulmonary bypass or during the first hours after surgery and is associated with a high early mortality 1,3,7-9. The Northern New England Cardiovascular Study group found that differences in postoperative mortality after CABG were mainly explained by differences in mortality rates caused by PHF ${ }^{1}$. Indeed, in a retrospective study performed by Algarni and his colleagues, 427 deaths in 25176 consecutive patients undergoing isolated CABG between 1990 and 2009 were investigated with respect to the predictor of PHF after isolated CABG, PHF was associated with a 17 to 29 -fold increase in mortality 8 . Similarly, PHF was associated with 25 -fold increase in mortality in patients undergoing isolated aortic valve replacement (AVR) 4.

In contrast to what was found in a mixed high-risk cohort undergoing AVR, our experience is that the serious consequences of PHF after isolated AVR for aortic stenosis (AS) become evident only after a few years 4, 7. PHF was found to be an independent risk factor for poor long-term survival7. We speculated that this could be explained by a previously undetected myocardial factor, possibly associated with myocardial fibrosis and diastolic dysfunction, that was unmasked by an episode of PHF 7.

In a study by Vanky and his colleagues, PHF after CABG was strongly associated with perioperative myocardial infarction and myocardial ischemia during the early stages of surgery, which could explain the high early mortality associated with PHF in $\mathrm{CABG}^{10}$. In patients undergoing AVR for AS 
an eliciting factor for PHF could only be identified in one third of the patients and myocardial ischemia played a subordinate role ${ }^{10}$.

Although PHF usually is easily recognizable in clinical practice, scientific evaluation of prevention and treatment represents a challenge as universally accepted criteria for the diagnosis of PHF are lacking ${ }^{11,12}$. Defining heart failure is difficult under any circumstance as was illustrated by a survey amongst reviewers of Cardiovascular research ${ }^{13}$. In cardiac surgery it may seem straightforward to rely on cardiac output measurements for the definition. However, cardiac output has to be assessed together with other hemodynamic variables since cardiac output can be very low despite a normal postoperative course due to low systemic oxygen demand in anesthetized patients early after surgery 14,15 .

Mixed venous oxygen saturation $\left(\mathrm{SvO}_{2}\right)$ reflects the balance between oxygen delivery to the tissues and systemic oxygen demand. Although, there are well-known pitfalls, $\mathrm{SvO}_{2}$ in the early postoperative course is well documented with regard to outcome ${ }^{16-18}$. However, $\mathrm{SvO} 2$ measurements require use of pulmonary artery catheters, which are rarely used routinely.

Echocardiography provides invaluable information in cardiac surgical practice about global and regional myocardial dysfunction and often reveals the underlying cause to heart failure ${ }^{19}$. However, echocardiography is investigator dependent and criteria for PHF may difficult to establish.

Reliance on treatment criteria for PHF, such as inotrope requirements or need for mechanical cardiac assist device are clouded by the large differences between geographical regions, institutions and individuals regarding threshold for institution of treatment or prophylaxis ${ }^{12,20}$. 
For study purposes, it would be desirable if currently available biomarkers for heart failure could be used to assess PHF and its severity.

\section{Natriuretic peptides}

There are three type of natriuretic peptides, brain natriuretic peptide, atrial natriuretic peptide and C-type natriuretic peptide in the natriuretic peptide family $^{21}$. In 1988, Sudoh et al. first isolated BNP from porcine brain tissue ${ }^{22}$. Several decades have passed since N-terminal pro-B-type natriuretic peptide (NT-proBNP) was first reported in human plasma by Hunt in $1995^{23}$.

Synthesis of pre-pro-BNP is initiated by myocyte stretch with increased wall stress response to volume expansion or pressure overload in the atrial and ventricular myocardium ${ }^{24}$. In cardiomyocytes, 108-amino precursor pro-B-type natriuretic peptide is cleaved and released as two molecules; an inactive 76-amino acid NT-proBNP fragment and a biologically active 32amino acid C-terminal BNP 25. Despite the 1:1 secretion of B-type natriuretic peptide (BNP) and NT-proBNP, BNP and NT-proBNP are not interchangeable ${ }^{26}$. The BNP has a half-life of approximately 20 min; while NTproBNP has a half-life ranging from 1 to $2 \mathrm{~h}$, leading to 5 - to 10 -fold greater circulating levels and slower fluctuations ${ }^{27,28}$. Natriuretic peptide receptor $\mathrm{C}$ and neutral endopeptidases present within renal tubular cells and vascular cells are involved in clearance of the peptides ${ }^{21}$. The physiologic function of BNP improves myocardial relaxation and counteracts the antidiuretic effects, sodium retention, and vasoconstriction caused by the activated renin-angiotensin-aldosterone system through coordinated actions in the brain, adrenal glands, kidneys, and vasculature ${ }^{21,26}$.

Ischemia also contributes to the release of natriuretic peptides, though it remains unclear to what extent this is caused by local myocardial stunning or ischemia per se ${ }^{29}$. 
In addition to ventricular wall stress and ischemia, there are some noncardiac factors that influence natriuretic peptide levels including advanced age, female gender, renal function, and obesity. In a population-based study, natriuretic peptide increased with age and was higher in women without known cardiovascular disease or detectable structural heart disease $^{30}$. Estrogen might be one of possible explanations for women with higher level natriuretic peptide ${ }^{30}$. The level of NT-proBNP increases with $38 \%$ for each $10 \mathrm{ml} \cdot \mathrm{min}^{-1} \cdot 1.73 \mathrm{~m}^{-2}$ decline in glomerular filtration rate ${ }^{31}$. This is not only caused by diminished renal clearance but also explained by a true counter-regulatory response from the heart to the kidney ${ }^{26}$. NTproBNP and BNP are lower in obese people regardless of heart failure ${ }^{26}$.

Inflammation, which was not addressed in this thesis, has also been reported as a stimulus of natriuretic peptides release in patients with septic shock or with endocarditis ${ }^{22} 33$. There might be several mechanisms responsible for elevated natriuretic peptides in inflammation, including increased ventricular filling pressure caused by septic cardiomyopathy ${ }^{2}$, proinflammatory cytokines like interleukin-1beta or tumor necrosis factoralpha that mediated myocardial depression 34 .

Acknowledging the influence of these factors might clarify the role of underlying heart disease per se for NT-proBNP levels and the prognostic utility of NT-proBNP in cardiac surgery.

\section{BNP and NT-proBNP in cardiology}

BNP and NT-proBNP have been established biomarkers for heart failure according to European Society of Cardiology (ESC) guidelines since 2005 35. In the PRIDE Study, NT-proBNP was found to be valuable for the identification and exclusion of acute congestive heart failure in the emergency 
department setting ${ }^{36}$. In a systematic review with a total of 48 studies reporting 15263 test results, BNP and NT-proBNP showed excellent ability to distinguish acute heart failure from non-cardiac causes of dyspnea at the rule out thresholds of $100 \mathrm{ng} \cdot \mathrm{L}^{-1}$ for BNP and $300 \mathrm{ng} \cdot \mathrm{L}^{-1}$ for NT- proBNP 37. In order to "rule in" heart failure, higher age-dependent cut points are suggested ${ }^{36}$. Patients with NT-proNP levels $>450$ pg $\mathrm{ml}^{-1}$ (<50 years), $>900 \mathrm{pg} \cdot \mathrm{ml}^{-1}$ (50-70 years), and $>1800 \mathrm{pg} \cdot \mathrm{ml}^{-1}(>75$ years $)$ all have a high likelihood of heart failure diagnosis ${ }^{8}$. Both the best cutoffs of "rule out" and "rule in" for acute heart failure apply to patients with acute dyspnea in the emergency department ${ }^{26}$.

Available studies also show that natriuretic peptides provide important prognostic information by distinguishing responders and non-responders to treatment of congestive heart failure 3940,41 . The most recent international guidelines recommend natriuretic peptides, particularly BNP or NTproBNP, to be used as first-line biomarkers for the diagnosis, prognosis, and follow-up of patients with heart failure ${ }^{42,43}$.

\section{Preoperative BNP and NT-proBNP in cardiac surgery}

A few studies report that preoperative natriuretic peptide levels differ between patients accepted for AVR, mitral valve surgery or CABG 44-46. However, these studies were either small or they did not adjust for non-cardiac confounders, such as preoperative renal function, age, gender, and obesity, which all have been reported to influence natriuretic peptides 30, 47-50. The role of underlying heart disease per se on the preoperative plasma levels of NT-proBNP thus has not been fully clarified. Increased knowledge about this influence could improve our interpretation of NT-proBNP in cardiac surgery and identify possible needs for homogenous patient cohorts when conducting studies on NT-proBNP in cardiac surgery. 
Preoperative natriuretic peptides are correlated to preoperative left ventricular ejection fraction (LVEF) and New York Heart Association (NYHA) class ${ }^{51}$. A considerable amount of literature has been published on the prognostic value of natriuretic peptide regarding outcome after cardiac surgery. In adult patients undergoing cardiac surgery elevated preoperative natriuretic peptides have been found to be associated with postoperative heart failure, adverse short-term outcome, such as long ventilation time, prolonged intensive care unit (ICU) stay, long hospital stay and postoperative mortality52-66. In 2009, Cuthbertson et al. investigated 1010 patients undergoing non-emergent cardiac surgery and demonstrated that preoperative NT-proBNP levels was an independent predictor for 30-day mortality after cardiac surgery even after adjusting for Parsonnet score and European system for cardiac operative risk evaluation score (EuroSCORE) 59. Four years later, in a large longitudinal study of the same cohort, preoperative NT-proBNP was found to independently predict 3-year mortality after cardiac surgery ${ }^{67}$. Furthermore, increased preoperative natriuretic peptides have been reported to be associated with hospitalization because of heart failure or cardiac death during 5-year follow-up after isolated $\mathrm{CABG}^{68}$. In addition, natriuretic peptides may be useful in congenital cardiac surgery ${ }^{69}$. However, it is unclear if the relationship between preoperative NT-proBNP and PHF or postoperative outcome is similar in the patients with coronary artery disease (CAD), aortic stenosis (AS) or mitral valve regurgitation (MR). Further investigation to assess the predictive value of preoperative NT-proBNP in these cohorts with regard to postoperative outcome might therefore be worthwhile.

Although BNP is an independent predictor of cardiac surgical outcome, it was not included in EuroSCORE II due to poor availability of data ${ }^{70}$. However, Holm et al. found combining preoperative NT-proBNP and EuroSCORE II may improve risk prediction with regard to severe PHF after isolated CABG for acute coronary syndrome (ACS) ${ }^{66}$. Preoperative BNP 
also was comparable and even better than logistic EuroSCORE in predicting long-term mortality in patients undergoing AVR for AS ${ }^{6}$.

\section{Postoperative BNP and NT-proBNP in cardiac surgery}

In adult patients undergoing cardiac surgery, both NT-proBNP and BNP increase postoperatively. NT-proBNP reached the peak on the fourth to seventh day ${ }^{71,72}$. The postoperative levels of NT-proBNP were similar in off-pump CABG and on-pump CABG 73. In patients without PHF, BNP peaked on POD3 then diminished, whereas BNP remained elevated without significant differences between POD3 and 5 in patients with PHF after CABG55.

High plasma concentrations of NT-proBNP and BNP postoperatively were associated with increased use of inotropic drugs and/or intra-aortic balloon pump ${ }^{2,55,71,73-76}$. High levels of natriuretic peptides were also reported to be associated with adverse short-term outcome, such as prolonged ICU stay, ventilation time, in-hospital mortality and postoperative mortality 72 , $73,77,78$.

A number of studies have reported the predictive value of postoperative natriuretic peptides with regard to long-term outcome (long-term mortality and major adverse cardiac events during follow-up) after cardiac surgery $44,76,77,79-81$. However, there are a limited number of studies specifically on postoperative natriuretic peptides and PHF in cardiac surgery (Table 1). 
Table 1. Studies on postoperative natriuretic peptides and PHF in cardiac surgery.

\begin{tabular}{|c|c|c|c|c|c|c|}
\hline Paper & Biomarker & Cohort & $\begin{array}{l}\text { Sample } \\
\text { size* }\end{array}$ & Design & PHF criteria & Results \\
\hline $\begin{array}{l}\text { Kerbaul } \\
2004^{51}\end{array}$ & NT-proBNP & $\begin{array}{l}\text { Off-pump } \\
\text { CABG }\end{array}$ & $21 / 60$ & prospective & Partly defined & $\begin{array}{l}\text { Early postop levels - } \\
\text { postop complications }\end{array}$ \\
\hline $\begin{array}{l}\text { Reyes } \\
2005^{71}\end{array}$ & NT-proBNP & mixed & $15 / 83$ & prospective & Treatment & $\begin{array}{l}\text { Postop levels higher } \\
\text { in patients treated } \\
\text { with inotropes }\end{array}$ \\
\hline $\begin{array}{l}\text { Provonchere } \\
2006^{66}\end{array}$ & BNP & Mixed & $30 / 92$ & prospective & Partly defined & $\begin{array}{l}\text { Postop day } 1 \text { levels } \\
\text { independently predict } \\
\text { post cardiac dysfunc- } \\
\text { tion }\end{array}$ \\
\hline $\begin{array}{l}\text { Fox } \\
2008^{55}\end{array}$ & BNP & $\mathrm{CABG}$ & $119 / 1023$ & prospective & Treatment & $\begin{array}{l}\text { Pre- and postop levels } \\
\text { higher in patients } \\
\text { with PHF }\end{array}$ \\
\hline $\begin{array}{l}\text { Suttner } \\
2008^{75}\end{array}$ & NT-proBNP & CABG & $32 / 98$ & prospective & Partly defined & $\begin{array}{l}\text { Postop day } 1 \text { inde- } \\
\text { pendently associated } \\
\text { with cardiac events }\end{array}$ \\
\hline $\begin{array}{l}\text { Nozohoor } \\
2009^{2}\end{array}$ & BNP & AVR & $37 / 161$ & prospective & Treatment & $\begin{array}{l}\text { BNP on arrival to } \\
\text { ICU predicted PHF }\end{array}$ \\
\hline
\end{tabular}

${ }^{*}$ Event number/sample size. AVR, aortic valve replacement; BNP, B-type natriuretic peptide; CABG, coronary artery bypass surgery; NT-proBNP, N-terminal pro-B-type natriuretic peptide; PHF, postoperative heart failure; Postop, postoperative.

\section{Treatment of postoperative heart failure}

Traditional treatment for PHF after cardiac surgery includes inotropic drugs, vasodilators, and mechanical circulatory support. Inotropes constitute common treatment for PHF but the use of inotropes in cardiac surgery differs markedly between institutions and individual physicians ${ }^{10-12} 82,83$. Inotropic treatment can enhance cardiac output and tissue oxygenation, but it also aggravates myocardial stress directly by a marked increase of myocardial oxygen demand and indirectly by increasing systemic oxygen demand ${ }^{15}$. This fact and the lack of generally accepted diagnostic criteria 
for PHF may explain why the evidence for current treatment of PHF with inotropes is poor. In fact, there are reports suggesting a detrimental effect if these drugs are used liberally or instituted early after severe myocardial ischemia ${ }^{12,84}$.

Inotropes may also carry hazards in patients undergoing AVR for AS since these drugs can trigger life-threatening left ventricular outflow tract obstruction in small and hypertrophied left ventricles if given in association with hypovolemia 85 .

Unloading of the heart with mechanical circulatory support theoretically provides a more beneficial myocardial oxygen demand / systemic oxygen delivery ratio but is resource demanding and associated with complications 1986,87 . These treatments are usually reserved for the sickest patients where they can be life saving ${ }^{19}$.

Metabolic support has received comparatively little attention in cardiac surgery for prevention and treatment of PHF although a large majority of studies show positive effects of glucose-insulin-potassium (GIK) and / or insulin that extend beyond simple metabolic benefits ${ }^{88}$.

\section{Glutamate}

Glutamate, which is one of the amino acids associated with malate-aspartate, plays a key role in myocardial metabolism particularly during myocardial ischemia ${ }^{89-91}$. Several biochemical mechanisms have been reported for glutamate's role of increasing myocardial tolerance to ischemia and enhancing myocardial recovery after ischemia.

During ischemia, glutamate improves myocardial tolerance to ischemia through its role in the malate-aspartate shuttle to facilitate anaerobic metabolism. Glutamate enhances glycolysis during ischemia by regulating the 
$\mathrm{NAD} / \mathrm{NADH}$ (nicotinamide adenine dinucleotide and nicotinamide adenine dinucleotide [reduced form]) balance in the cytosol of the cells by transport of reducing equivalents across the mitochondrial membrane. Glutamate contributes to an alternative anaerobic pathway for regeneration of high-energy phosphates by substrate level phosphorylation in the Krebs cycle. Glutamate improves the clearance of lactate and $\mathrm{NH}_{3}$ excess by taking part in the reactions involving transamination of pyruvate to alanine and of glutamate to glutamine. After ischemia glutamate contributes to replenishment of Krebs cycle intermediates lost during ischemia to enhance post-ischemic myocardial recovery $89,90,92$.

In humans it has been shown that patients with CAD have increased demands of glutamate 93-97. Infusion of glutamate to patients with ischemic heart disease delayed onset of angina and ST-changes during pacing and exercise testing ${ }^{98}$. Glutamate enriched blood cardioplegia improved ATP preservation in human myocardium and provided more effective myocardial protection 99 . Infusion of glutamate after coronary surgery has been reported to enhance both metabolic and hemodynamic myocardial recovery 100, 101. In the GLUTAmate for Metabolic Intervention in Coronary Surgery trial (GLUTAMICS)-trial, glutamate infusion was associated with a reduced risk of developing severe heart failure in high-risk groups ${ }^{102}$. For the final paper of this thesis our hypothesis was that glutamate facilitates myocardial recovery in post-ischemic heart failure and, therefore, will be accompanied by a mitigated postoperative increase of NT-proBNP. 


\section{AIMS OF THE DISSERTATION}

- To investigate the impact of underlying heart disease on preoperative NT-proBNP levels in patients admitted for first time surgery because of $\mathrm{CAD}, \mathrm{AS}$, and MR after adjusting for known non-cardiac confounders age, gender, obesity and renal function.

- To investigate the predictive value of preoperative NT-proBNP in CAD, AS and MR cohorts with regard to severe PHF.

- To investigate the predictive value of preoperative NT-proBNP in CAD, AS and MR cohorts with regard to postoperative mortality.

- To investigate the predictive value of preoperative NT-proBNP on long-term survival after elective AVR for AS.

- To investigate the association between postoperative NT-proBNP and PHF in patients undergoing elective AVR for AS.

- To investigate the impact of PHF and postoperative NT-proBNP on long-term survival after elective AVR for AS.

- To investigate the association between postoperative NT-proBNP and PHF and its severity after isolated CABG for acute coronary syndrome.

- To investigate the impact of glutamate infusion on postoperative NTproBNP levels in patients undergoing CABG for acute coronary syndrome. 


\section{MATERIAL AND METHODS}

\section{Patients}

An overview of the patients in Paper I - IV is presented in Table 2.

Table 2. Basic data on patients included in the study.

\begin{tabular}{|c|c|c|c|c|}
\hline Paper & $\begin{array}{c}\text { I } \\
\text { CAD/MR/AS -NT- } \\
\text { proBNP }\end{array}$ & $\begin{array}{c}\text { II } \\
\text { NT-proBNP - } \\
\text { AVR }\end{array}$ & $\begin{array}{c}\text { III } \\
\text { NT-proBNP - } \\
\text { CABG }\end{array}$ & $\begin{array}{c}\text { IV } \\
\text { Glutamate - } \\
\text { NT-proBNP }\end{array}$ \\
\hline Study design & $\begin{array}{l}\text { Retrospective cohort } \\
\text { analysis }\end{array}$ & $\begin{array}{l}\text { Prospective co- } \\
\text { hort analysis }\end{array}$ & $\begin{array}{l}\text { Prospective co- } \\
\text { hort analysis }\end{array}$ & $\begin{array}{l}\text { Randomized } \\
\text { clinical trial }\end{array}$ \\
\hline Procedure & $\begin{array}{l}\text { isolated CABG, iso- } \\
\text { lated AVR, mitral } \\
\text { valve surgery due to } \\
\text { MR }\end{array}$ & AVR for AS & isolated $\mathrm{CABG}$ & $\begin{array}{l}\mathrm{CABG}+ \\
\text { concomitant } \\
\text { procedure }\end{array}$ \\
\hline Indication & $\begin{array}{l}\text { CAD, AS without AR, } \\
\text { MR without MS }\end{array}$ & AS & ACS & ACS \\
\hline No of patients & 2978 & 203 & 382 & 399 \\
\hline Age(years) & $70[63-76]$ & 70 [65-77] & 69 [62-75] & 69 [63-75] \\
\hline Female & $24 \%(714)$ & $50 \%(102)$ & $19 \%(73)$ & $19 \%(73)$ \\
\hline Preop eGFR & $73[60-86]$ & 68 [58-82] & 76 [58-97] & 76 [58-97] \\
\hline $\begin{array}{l}\text { Severe LV } \\
\text { dysfunction }\end{array}$ & $4 \%(134)$ & $2 \%(5)$ & $4 \%(14)$ & $4 \%(16)$ \\
\hline $\begin{array}{l}\text { Additive Eu- } \\
\text { roSCORE }\end{array}$ & $4[3-6]$ & 6 [4-7] & 5 [3-7] & 5 [3-7] \\
\hline EuroSCORE II & N/A & $1.6[1.1-2.8]$ & 2.4 [1.6-3.9] & $2.4[1.7-4.2]$ \\
\hline $\begin{array}{l}\text { Follow-up time } \\
\text { (years) }\end{array}$ & $\begin{array}{l}30 \text { days/ } \\
\text { hospital stay }\end{array}$ & $8.6 \pm 1.1$ & $\begin{array}{l}30 \text { days/ } \\
\text { hospital stay }\end{array}$ & $\begin{array}{l}30 \text { days/ } \\
\text { hospital stay }\end{array}$ \\
\hline PHF & N/A & $9 \%(18)$ & $9 \%(35)$ & $10 \%(40)$ \\
\hline $\begin{array}{l}\text { Severe PHF } \\
\text { Postoperative } \\
\text { mortality* }\end{array}$ & $4 \%(130)$ & $0.5 \%$ & $2 \%(6)$ & $3 \%(10)$ \\
\hline 30-day mortality & $1 \%(39)$ & $0.5 \%(1)$ & $1 \%(4)$ & $1 \%(4)$ \\
\hline
\end{tabular}

Data given as medians [interquartile range], mean \pm standard deviation or percentages (number). ACS, acute coronary syndrome; AS, aortic stenosis; AVR, aortic valve replacement; CAD, conorary artery disease; CABG, coronary artery bypass surgery; eGFR, estimated glomerular filtration rate according to MDRD formula; EuroSCORE, European system for cardiac operative risk evaluation; LV, left ventricular; N/A, not available; NTproBNP, N-terminal pro-B-type natriuretic peptide; MR, mitral regurgitation; PHF, postoperative heart failure. $*$ Including hospital mortality. 


\section{Paper I and II}

The University Hospital in Linköping is the only referral center in the southeast region of Sweden, serving a population of approximately 1 million. In Paper I and Paper II the study population consisted of patients belonging to this referral area operated at this cardiothoracic center.

\section{Paper I}

From April 30, 2010, to August 31, 2016, 2289 patients underwent first time isolated $\mathrm{CABG}$ for $\mathrm{CAD}, 570$ patients underwent isolated aortic valve surgery for aortic valve disease and 446 patients underwent mitral valve surgery for mitral valve disease at this department. Exclusion criteria were: aortic valve regurgitation ( $n=109)$, acute endocarditis $(n=65)$, endocarditis after previous surgery $(n=11)$, redo procedures $(n=63)$, mitral valve stenosis $(n=33)$ and missing preoperative NT-proBNP values $(n=46)$. Concomitant tricuspid valve or Maze procedures were not exclusion criteria. From this cohort, we included 2978 consecutive patients admitted for first time isolated CABG for CAD ( $\mathrm{n}=\mathbf{2 2 2 6})$, isolated AVR because of AS without significant aortic regurgitation $(n=406)$ or mitral valve surgery due to $M R$ without mitral valve stenosis $(\mathrm{n}=346)$.

\section{Paper II}

Between June 2008 and January 2013, 203 patients were prospectively included in a prespecified substudy of the original prospective observational study ${ }^{103}$. Inclusion criteria were consecutive patients who provided written informed consent and were scheduled to undergo AVR for AS. Exclusion criteria were: active endocarditis or emergency procedure $(n=86)$, surgery for aortic regurgitation $(n=43)$ or equally significant AS and aortic regurgitation $(n=5)$, transcatheter aortic valve implantation (TAVI) $(n=126)$, concomitant CABG $(n=75)$, concomitant MAZE procedure $(n=5)$, concomitant mitral valve surgery $(n=5)$, or a lack of informed written consent. Concomitant tricuspid valve procedure $(n=5)$ or replacement of ascending aorta 
with a supracoronary graft that did not require circulatory arrest $(n=26)$ were not exclusion criteria.

\section{Paper III and IV}

The study population consisted of patients who were prospectively enrolled in a substudy of the GLUTAMICS-trial (ClinicalTrials.gov Identifier: NCTo0489827) between May 2007 and November 2009, at three Swedish Cardiac Surgery centers (Linköping University Hospital, Örebro University Hospital, and Karlskrona Hospital) ${ }^{102}$.

Inclusion criteria were CABG for ACS. Patients were eligible for inclusion regardless if the procedure was done on-pump or off-pump. Exclusion criteria were informed consent not possible because of critical condition or other reason, age $>85$ years, redo-procedure, preoperative dialysis, preoperative use of inotropic drugs or mechanical circulatory assist, unexpected intraoperative finding or event that increased the magnitude of the procedure to overshadow the originally planned operation, body weight $>$ $125 \mathrm{~kg}$ and food allergy known to have caused flush, rash or asthma.

\section{Paper III}

382 consecutive patients with ACS undergoing urgent isolated first-time CABG in a double-blind randomized clinical trial (GLUTAMICS-trial) were included. 17 patients were excluded because of CABG with concomitant procedure.

Comment: Patients having additional procedures have substantially higher levels of natriuretic peptides both preoperatively and postoperatively ${ }^{77}$. In order to keep a homogeneous cohort in this observational substudy, only patients with isolated CABG were included in contrast to Paper IV where a double-blind randomized design was employed. 


\section{Paper IV}

399 consecutive patients with parallel assignment to intravenous infusion of glutamate $(\mathrm{n}=200)$ or placebo (saline) $(\mathrm{n}=199)$ undergoing urgent firsttime CABG with or without concomitant procedure for ACS in a doubleblind randomized clinical trial (GLUTAMICS-trial) were included.

\section{Clinical management}

\section{Paper I and II}

After an overnight's fast drugs were withheld with the exception of betablockers and calcium antagonists. Oxycodone 4-10 mg and scopolamine 0.2-0.5 mg intramuscularly were given as premedication. Thiopentone $1 \mathrm{mg} \cdot \mathrm{kg}^{-1} \mathrm{BW}$ and fentanyl $30 \mathrm{mg} \cdot \mathrm{kg}^{-1} \mathrm{BW}$ were used to induce anesthesia. Neuromuscular blockade was achieved with rocuronium, 50mg at induction and 3omg at sternal closure. Fentanyl and isoflurane were used to maintain anesthesia.

Standard surgical techniques were employed with cardiopulmonary bypass (CPB) and aortic cross clamping. Heparin $3 \mathrm{mg} \cdot \mathrm{kg}^{-1} \mathrm{BW}$ was given intravenously before $\mathrm{CPB}$ to obtain an activated clotting time $>480$ s. Priming of the extracorporeal circuit was achieved with Ringer's acetate and mannitol. Moderate hemodilution (hematocrit 20-25\%) and mild hypothermia (33$36^{\circ} \mathrm{C}$ ) were usually employed. Myocardial protection was achieved with antegrade delivery of cold crystalloid cardioplegic solution. Weaning from $\mathrm{CPB}$ was started at a rectal temperature of $35-36^{\circ} \mathrm{C}$. Protamine chloride 1:1 (weight) was used to neutralize heparin. Ringer's acetate was used for volume substitution postoperatively. Seventy patients were operated off pump (Paper I). 


\section{Paper III and IV}

Clinical management was standardized and similar at the three participating centers with minor differences concerning choice of anesthetic drugs. The patients received beta-blockers and calcium antagonists orally after an overnight's fast whereas antihypertensive and antidiabetic agents were withheld. Standard premedication consisted of orally administered flunitrazepam 0.5-1.0 mg or diazepam 5-10 $\mathrm{mg}$ and ketobemidone 0.1-0.2 $\mathrm{mg} \cdot \mathrm{kg}^{-1}$ body weight (BW) or morphine 0.1-0.2 $\mathrm{mg} \cdot \mathrm{kg}^{-1} \mathrm{BW}$. Thiopentone (2-3 $\mathrm{mg} \cdot \mathrm{kg}^{-1} \mathrm{BW}$ ) or propofol ( $2 \mathrm{mg} \cdot \mathrm{kg}^{-1} \mathrm{BW}$ ) supplemented by a bolus dose of fentanyl 3-5 $\mu \mathrm{g} \cdot \mathrm{kg}^{-1} \mathrm{BW}$ was used to induce anesthesia. Pancuronium 0.1 $\mathrm{mg} \cdot \mathrm{kg}^{-1} \mathrm{BW}$ or rocuronium $0.6 \mathrm{mg} \cdot \mathrm{kg}^{-1} \mathrm{BW}$ was used for muscle relaxation. Isoflurane, sevoflurane or propofol supplemented with intermittent doses of fentanyl were used to maintain anesthesia.

Standard monitoring consisted of pulse oximetry, continuous arterial blood pressure monitoring, central venous pressure, 5-lead echocardiogram, and transesophageal echocardiography. All patients received a surgical pulmonary artery catheter ${ }^{18}$.

A median sternotomy was performed in all patients. CPB and aortic crossclamping was employed in most patients with the exception of twelve who were operated off pump. Myocardial protection was achieved with cold blood cardioplegia in the majority of patients operated on pump. One center used cold crystalloid cardioplegia during the first half of the trial.

Propofol was used for postoperative sedation. Intravenous administration of ketobemidone 7-15 $\mu \mathrm{g} \cdot \mathrm{kg}^{-1} \mathrm{BW}$ intermittently and acetaminophen $1 \mathrm{~g}$ every 6th hour was used for postoperative analgesia.

The patients were extubated when the following conditions were achieved: body temperature $>37^{\circ} \mathrm{C}$, stable hemodynamics including $\mathrm{SvO}_{2}>55 \%$, 
$\mathrm{PO}_{2}>10 \mathrm{kPa}$ with $\mathrm{FiO}_{2} 0.4$ and $\mathrm{PCO}_{2}<6.5 \mathrm{kPa}$ with a respiratory rate $<30$ and drainage loss $<100 \mathrm{ml}$ per hour and declining.

After discharge from the ICU patients were transferred to a step-down semi-intensive care unit for at least 24 hours before going to the general ward.

\section{Surgical pulmonary artery catheter}

According to clinical routine the surgeon introduced a pulmonary artery catheter in every patient before weaning from CPB for monitoring of pulmonary artery pressure and intermittent blood sampling for $\mathrm{SvO}_{2}$ (Paper I to IV). An epidural needle was used to puncture the outflow tract of the right ventricle and then an epidural catheter cut $5 \mathrm{~cm}$ from its tip (PerifixKatheter, B.Braun Melsungen AG, Germany) was introduced approximately $15 \mathrm{~cm}$ into the pulmonary artery. A 4-0 prolene purse string suture was gently tightened around the puncture site to minimize risk for bleeding at withdrawal, which was usually done the next morning before the withdrawal of the chest tubes ${ }^{18}$.

\section{Study protocol}

\section{Paper I}

Paper I was designed as retrospective cohort study. NT-proBNP was routinely measured the day before surgery in elective patients and on the day of surgery in emergency patients. Demographic and perioperative data were registered prospectively in a computerized institutional database (Carath version 5.4, Fujitsu Inc.). Mortality data were retrieved from the Swedish Civil registry. 
The 2978 consecutive patients undergoing first time surgery for CAD $(\mathrm{n}=2226), \mathrm{AS}(\mathrm{n}=406)$ or MR $(\mathrm{n}=346)$ included in the study were followed 90 days. Multivariable linear regression was used to assess the role of underlying heart disease on NT-proBNP levels at admission to surgery. Multivariable logistic regression was used to identify preoperative and intraoperative risk factors for severe PHF and postoperative mortality.

Comment: The timing of surgery and referral selection bias might have an impact on the level of natriuretic peptides. However, availability of cardiac surgical resources permitted most patients to be treated according to current guidelines 104, 105. Referral selection bias was minimized as the study included virtually all patients operated for CAD, AS and MR during a five-year period in southeastern Sweden.

Paper I has been published in a previous thesis (Linköping Medical Dissertations No. 1680) by Henrik Hultkvist who is co-author. The individual contributions of the autors are given in Paper I.

\section{Paper II}

This was designed as prospective, observational, longitudinal study evaluating the association between NT-proBNP and PHF after elective first-time AVR for AS. Plasma NT-proBNP was assessed at preoperative evaluation, the day before surgery, the first (POD1) and third postoperative morning (POD3), and at the six-month follow-up. A Clinical Endpoints Committee, blinded to NT-proBNP results, used prespecified hemodynamic criteria to diagnose PHF. Demographic and perioperative data were registered prospectively in a computerised institutional database (Carath version 5.4, Fujitsu Inc.). Mortality data were retrieved from the Swedish Civil registry. 203 patients undergoing elective first-time AVR for AS were followed on average $8.6 \pm 1.1$ years (range 6.5 - 10.5 years). A receiver operating characteristic (ROC) analysis was carried out to evaluate the discrimination of NT-proBNP for PHF. Multivariable logistic regression was used to identify 
risk factors and predictors for PHF. Cox proportional hazards regression models were done to identify risk factors for mortality during follow-up.

\section{Paper III}

Paper III was designed as prospective observational study investigating if postoperative NT-proBNP can be used for assessment of PHF in patients undergoing CABG for ACS. Plasma NT-proBNP was measured preoperatively, on POD1 and POD3. A Clinical Endpoints Committee, blinded to NT-proBNP, used prespecified criteria relying mainly on mixed venous oxygen saturation to diagnose PHF and severe PHF. 382 consecutive patients from the GLUTAMICS-trial undergoing isolated CABG for acute coronary syndrome were included in the study. Multivariable linear regression was done to assess the role of PHF or severe PHF on postoperative NT-proBNP levels. ROC analysis was carried out to evaluate discrimination of postoperative NT-proBNP and its trends with regard to PHF and severe PHF respectively. Multivariable logistic regression was used to analyze predictors for PHF.

\section{Paper IV}

Paper IV was designed as a prespecified substudy of an investigator-initiated, prospective, double-blind randomized clinical trial, the GLUTAMICS-trial to assess the influence of intravenous glutamate infusion on postoperative NT-proBNP levels in patients undergoing CABG for acute coronary syndrome. Plasma NT-proBNP was measured preoperatively, on POD1 and POD3. A Clinical Endpoints Committee, blinded to both intervention and NT-proBNP used prespecified criteria to diagnose PHF. 399 patients with parallel assignment to intravenous infusion of glutamate $(\mathrm{n}=\mathbf{2 0 0})$ or placebo (saline) $(\mathrm{n}=199)$ undergoing CABG with or without concomitant procedure for acute coronary syndrome were included. Multivariable linear regression was used to assess the role of glutamate on postoperative NT-proBNP level. 
Comment: Paper III - IV constitute prespecified substudies from the GLUTAMICS-trial using NT-proBNP with different objectives.

\section{Methods}

\section{NT-proBNP measurement}

Sampling for NT-proBNP was done at preoperative evaluation (Paper II), the day before surgery (Paper I and II), on the day of surgery in emergency patients (Paper I), immediately before induction of anesthesia (Paper III and IV), the first and third postoperative morning (Paper II, III and IV) and at the six-month follow-up (Paper II).

Venous blood samples were collected in lithium heparin tubes and analyzed within 1 hour (emergency) to 3 hours (elective patients). NT-proBNP was measured in plasma by electro-chemoiluminescence immunoassay on a Roche Elecsys 2010 automated platform (Roche Diagnostics, Basel, Switzerland). The assay had an effective measuring range of 5-35000 $\mathrm{ng} \cdot \mathrm{L}^{-1}$. The inter-assay coefficient of variation was at $175 \mathrm{ng} \cdot \mathrm{L}^{-1} \mathrm{CV}=2.7 \%, 355 \mathrm{ng} \cdot \mathrm{L}^{-}$ ${ }^{1} \mathrm{CV}=2.4 \%$ and $1068 \mathrm{ng} \cdot \mathrm{L}^{-1} \mathrm{CV}=\mathbf{1 . 9 \%}$. The results of the assays were released from the laboratory when the trial was terminated (Paper II, III and IV). The following upper reference limits (URLs) were applied: $450 \mathrm{ng} \cdot \mathrm{L}^{-1}$ for $<50$ years, $900 \mathrm{ng} \cdot \mathrm{L}^{-1}$ for $50-75$ years, and $1800 \mathrm{ng} \cdot \mathrm{L}^{-1}$ for $>75$ years. Values $<300 \mathrm{ng} \cdot \mathrm{L}^{-1}$ were considered normal in all age groups and the intervals between $300 \mathrm{ng} \cdot \mathrm{L}^{-1}$ and the URL for the age group were considered a grey zone 26,37 . 


\section{Mixed venous oxygen saturation $\left(\mathrm{SvO}_{2}\right)$ measurement}

Sampling for $\mathrm{SvO}_{2}$ was done after weaning from cardiopulmonary bypass, on admission to ICU and whenever unstable hemodynamics was suspected (Paper I-IV).

Mixed venous blood was drawn from a surgical pulmonary artery catheter. $\mathrm{SvO}_{2}$ was measured in ABL 725 (Radiometer Medical Aps, Brønshøj, Denmark) or ABL 825 (Radiometer Medical Aps, Brønshøj, Denmark -Paper I and II); or an ABL 500 (Radiometer Medical Aps, Brønshøj, Denmark Papers III, IV). Prespecified $\mathrm{SvO}_{2}$ criteria were used by blinded Clinical Endpoints Committee to diagnose PHF in Paper II, III and IV.

\section{EuroSCORE calculations}

Additive EuroSCORE was automatically calculated in all studies by an algorithm in the institutional database (Carath version 5.4, Fujitsu Inc.). EuroSCORE II was calculated retrospectively for each patient with the EuroSCORE II interactive calculator at www.euroscore.org (Paper II, III and IV).

\section{Definitions}

\section{Postoperative heart failure}

\section{Paper II, III and IV}

Postoperative heart failure was considered present if criteria $a+b$ were fulfilled. a) Decision reached by the Endpoints committee that heart failure was evident at weaning from cardiopulmonary bypass or during the early hours after surgery based on criteria below and supported by available clinical records, echocardiography and hemodynamic data. b) $\mathrm{SvO}_{2}$ criteria in relation to systolic arterial pressure (SAP) that could not be explained by 
shivering, anemia or hypovolemia. The criteria were based on extensive studies on $\mathrm{SvO}_{2}$ with regard to outcome and clinical experience regarding the approximate relationship between $\mathrm{SvO}_{2}$ and $\mathrm{SAP}$ while using fast acting vasodilator nitroprusside. $\mathrm{SvO}_{2}<50 \%$ and $\mathrm{SAP}<130 \mathrm{mmHg} ; \mathrm{SvO}_{2}<55 \%$ and SAP < $110 \mathrm{mmHg} ; \mathrm{SvO}_{2}<60 \%$ and SAP < $90 \mathrm{mmHg}{ }^{16-18,100}$.

\section{Severe postoperative heart failure}

Due to lack of generally accepted criteria for severe postoperative heart failure, severe postoperative heart failure had to be defined based on available data in the retrospective study (Paper I). In the prospective studies, a blinded Clinical endpoints committee relied on prespecified criteria to diagnose severe postoperative heart failure (Paper II, III and IV).

\section{Paper I}

Severe postoperative heart failure was defined as clinical diagnosis in the medical records and/or echocardiographic signs of heart failure and an ICU stay $\geq 72$ hours or hospital mortality with one of the following: intra-aortic balloon pump or ventricular assist device, or the use of inotropes (adrenaline $\geq 3 \mu \mathrm{g} \cdot \mathrm{min}^{-1}$; milrinone $\geq 0.375 \mu \mathrm{g} \cdot \mathrm{kg}^{-1} \cdot \mathrm{min}^{-1}$; need for two inotropes at any dosage; or use of levosimendan at any dosage).

Comment: Because of the retrospective nature of the study and the large number of patients that had to be reviewed, ICU stay larger than 72 hours (as opposed to 48 hours in the prospective studies) was used to distinguish patients with severe PHF. In retrospect it seems that CABG patients in the prospective studies and the retrospective study with severe PHF were fairly comparable regarding severity.

\section{Paper II, III and IV}

Severe postoperative heart failure was defined as PHF leading to death or an extended ICU stay ( $\geq 48$ hours) in patients requiring treatment with an intra-aortic balloon pump or at least one inotropic agent with the following 
dosages $\geq 24 \mathrm{~h}$ after admission to the ICU: epinephrine $\geq 0.033 \mu \mathrm{g} \cdot \mathrm{kg}^{-1} \cdot \mathrm{min}^{-}$ ${ }^{1}$, milrinone $\geq 0.375 \mu \mathrm{g} \cdot \mathrm{kg}^{-1} \cdot \mathrm{min}^{-1}$, dopamine $\geq 4 \mu \mathrm{g} \cdot \mathrm{kg}^{-1} \cdot \mathrm{min}^{-1}$, dobutamine $\geq 4 \mu \mathrm{g} \cdot \mathrm{kg}^{-1} \cdot \mathrm{min}^{-1}$, or levosimendan regardless of dose.

\section{LV dysfunction}

A preoperative LV ejection fraction (LVEF) of 0.30 or less according to echocardiography was classified as severe left ventricular dysfunction whereas a LVEF of 0.31 - 0.45 was classified as moderate LV dysfunction.

\section{Postoperative mortality}

Postoperative mortality was defined as the rate of death from any cause within 30 days after cardiac surgery, or death from any cause later during the same hospitalization period, including discharge to the referral hospital. Medical records were scrutinized for all patients dying within 90 days of surgery. Mortality data were retrieved from the Swedish Civil registry. The cause of death was retrieved from medical records and usually supported by autopsy.

\section{Hospital mortality}

Hospital mortality was defined as mortality during the first hospitalization period. This included postoperative stay at the referral hospital as a substantial proportion of patients were discharged to their county hospitals.

\section{Statistics}

Data are presented as percentages or mean \pm standard deviation or median [interquartile range]. Continuous variables not following a normal distribution, were analysed with Mann-Whitney U test (Paper I, II, III and IV) 
and Wilcoxon signed ranks test were used (Paper II and III). Kruskal-Wallis test and pairwise comparison test was used for comparison continuous variables among three groups (Paper I). Pearson Chi-square test was used to compare proportions and to account for multiple testing the Bonferroni correction was used (Paper I). Categorical data were compared with Fisher's exact test (Paper II, III and IV). Statistical significance was defined as $\mathrm{p}<0.05$. All $\mathrm{p}$-values were two-sided.

Multivariable linear regression was used to assess the association between two or more independent variables and a single continuous dependent variable (Paper I, III and IV).

Multivariable logistic regression was done with a backward (conditional) stepwise (Paper I, II and III). Hosmer-Lemeshow goodness-of-fit statistics were calculated for the final model (Paper I, II and III). Predictive value was assessed with ROC analysis (Paper I, II and III). Youden's index was used for calculation of best cutoff point with regard to sensitivity and specificity (Paper I, II and III)

Survival curves were generated by means of Kaplan-Meier estimates, and differences in survival were compared with the log-rank test (Paper II). Cox proportional hazards regression models were used to identify risk factors for mortality during follow-up (Paper II).

Statistical analyses were performed with SPSS statistics version 23 (IBM) for windows (Paper I, II, III and IV) and Statistica 13.2, Dell Inc (Paper I), Statistica 12.o (StatSoft Inc., Tulsa, OK) (Paper II and III).

\section{Ethics}

All studies were performed according to the Helsinki Declaration of $\mathrm{Hu}-$ man Rights and the studies in Paper III-IV were conducted according to 
Good Clinical Practice (GCP) standard. All studies were approved by the Regional Ethical Review Board in Linköping, Sweden (Paper I: Dnr 2011/ 497-31; Paper II: M 198-07, T 126-o8, 2012/422-32; Paper III and IV: original protocol no M76-05; addendum 26-07). The patients were enrolled in the studies after written informed consent was obtained (Paper II, III and IV) with the exception of Paper I. Owing to the nature of that study; the ethics committee waived the need for written informed consent. 


\section{RESULTS}

\section{Preoperative NT-proBNP and underlying heart dis- ease (Paper I)}

Paper I was based on retrospective cohort analysis. Among all 2978 patients, the median age was 70 [63-76] years and $24 \%$ were female. The median Additive EuroSCORE was 4 [3-6]. Age, hemoglobin, albumin, proportion of moderate or severe LV dysfunction, atrial fibrillation, and obesity were significantly different among patients with CAD, AS, and MR. Details are given in Table 1 of Paper I.

NT-proBNP was higher in patients with AS than in patients with CAD (595 [260-1510] vs 290 [120-833] ng. $\mathrm{L}^{-1}, \mathrm{p}<0.0001$ ) or patients with MR (400 [110-1350] ng $\left.\cdot \mathrm{L}^{-1}, \mathrm{p}<0.0001\right)$. After adjusting for age, eGFR, female gender, and obesity, NT-proBNP was 1.67 times higher in patients with AS than in patients with CAD (adjusted coefficient 0.223, 95\%CI 0.160-0.285; $\mathrm{p}<0.0001)$ and 1.41 times higher in patients with MR than patients with CAD (adjusted coefficient 0.150, 95\%CI 0.085-0.215, p<0.0001; Table 3).

Table 3. Multivariable linear regression results for $\log _{10}$ NTproBNP Preop in all patients.

\begin{tabular}{llll}
\hline Variable & Adjusted coefficient & $\mathbf{9 5 \% C I}$ & $\mathbf{p}$ \\
\hline Age $($ years $)$ & 0.020 & $0.018-0.022$ & $<0.0001$ \\
Preop eGFR $\left(\mathrm{mL} \cdot \mathrm{min}^{-1} \cdot 1.73 \mathrm{~m}^{-2}\right)$ & -0.006 & $-0.007--0.005$ & $<0.0001$ \\
Male & ref & & \\
Female & 0.114 & $0.064-0.164$ & $<0.0001$ \\
CAD & ref & & \\
MR & 0.150 & $0.085-0.215$ & $<0.0001$ \\
AS & 0.223 & $0.160-0.285$ & $<0.0001$ \\
\hline
\end{tabular}

Adjusted $\mathrm{R}^{2}=0.215$, ANOVA for the model $(\mathrm{df}=5, \mathrm{~F}=164.162, \mathrm{p}<0.0001)$. CI, confidence interval; eGFR, estimated glomerular filtration rate according to MDRD formula; CAD, coronary artery disease; AS, aortic valve stenosis; MR, mitral valve regurgitation. 


\section{Preoperative NT-proBNP and severe postoperative}

\section{heart failure (Paper I)}

A total of 130 patients had severe PHF (88 patients with CAD, 14 patients with AS, 28 patients with MR). According to ROC analysis, preoperative NT-proBNP demonstrated significant discriminatory power with regard to severe $\mathrm{PHF}$ in patients with $\mathrm{CAD}$ (area under the curve (AUC) $=0.79,95 \% \mathrm{CI}$ $0.73-0.85, \mathrm{p}<0.0001$ ), MR (AUC $=0.80,95 \% \mathrm{CI} 0.72-0.87, \mathrm{p}<0.0001)$ and AS (AUC=0.66, 95\%CI 0.51-0.81, p=0.047; Figure 1). The best cutoffs according to Youden's index were $855 \mathrm{ng} \cdot \mathrm{L}^{-1}$ (sensitivity $73 \%$, specificity $77 \%$ ) in CAD patients, $975 \mathrm{ng} \cdot \mathrm{L}^{-1}$ (sensitivity $71 \%$, specificity 65\%) in AS patients and $800 \mathrm{ng} \cdot \mathrm{L}^{-1}$ (sensitivity $82 \%$, specificity $69 \%$ ) in MR patients.

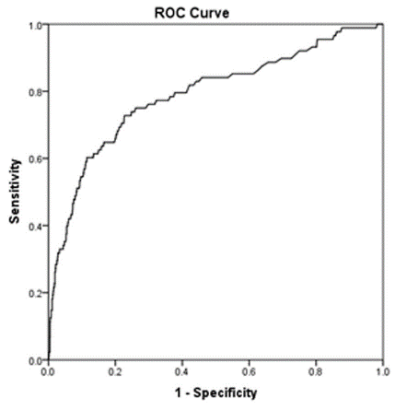

A

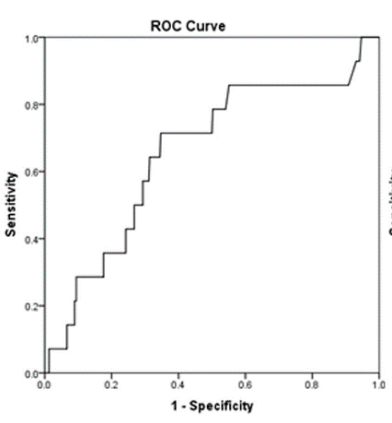

B

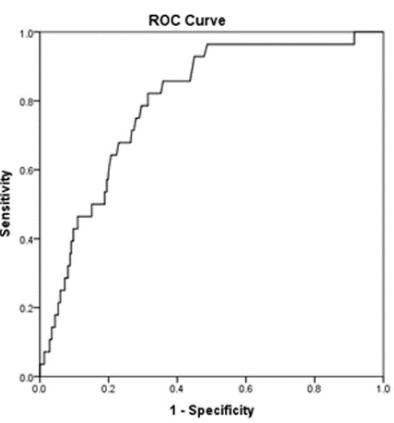

$\mathrm{C}$

Figure 1. Discrimination of preoperative NT-proBNP with regard to severe PHF in patients with CAD, AS, and MR. Preoperative NT-proBNP demonstrated significant discrimination according to ROC analysis with regard to severe PHF in patients with CAD (A: AUC $=0.79,95 \%$ CI $0.73-0.85, \mathrm{p}<0.0001$; best cutoff 855 $\mathrm{ng} \cdot \mathrm{L}^{-1}$ with a sensitivity of $73 \%$ and a specificity of $77 \%$ ), AS (B: AUC $=0.66$, $95 \%$ CI $0.51-0.81, \mathrm{p}=0.047$; best cutoff $975 \mathrm{ng} \cdot \mathrm{L}^{-1}$ with a sensitivity of $71 \%$ and specificity of $65 \%$ ), and MR (C: AUC $=0.80,95 \%$ CI $0.72-0.87, \mathrm{p}<0.0001$; best cutoff $800 \mathrm{ng} \cdot \mathrm{L}^{-1}$ with a sensitivity of $82 \%$ and specificity of $69 \%$ ). ROC, receiver operating characteristics; severe PHF, severe postoperative heart failure; AUC, area under the curve; $\mathrm{CI}$, confidence interval.

In the multivariable analysis, NT-proBNP $\geq 855 \mathrm{ng} \cdot \mathrm{L}^{-1}$ emerged as an independent risk factor for severe PHF in patients with CAD (adjusted Odds 
ratio (OR) 2.87, 95\% CI 1.56-5.30, $\mathrm{p}=0.001$ ). Age, preoperative dialysis, aortic cross-clamp time in upper quartile ( $\geq 62 \mathrm{~min}$ ), moderate to severe $\mathrm{LV}$ dysfunction, NYHA IV, insulin-treated diabetes, critical preoperative state, and emergency operation were the other variables in the final model (Table 4). The number of events was too few to permit multivariable analysis in patients with AS or MR.

Table 4. Multivariable analysis* of risk factors for severe PHF in CAD patients.

\begin{tabular}{llll}
\hline Variable & Odds ratio & $\mathbf{9 5 \% C I}$ & $\mathbf{p}$ \\
\hline Age (years) & 1.05 & $1.01-1.08$ & 0.005 \\
Preoperative dialysis & 23.1 & $6.47-82.2$ & $<0.0001$ \\
Preop NT-proBNP $\geq 855 \mathrm{ng} \cdot \mathrm{L}^{-1}$ & 2.87 & $1.56-5.30$ & 0.001 \\
Cross-clamp time upper quartile $(\geq 62 \mathrm{~min})$ & 3.04 & $1.78-5.18$ & $<0.0001$ \\
Moderate to severe LV dysfunction & 2.69 & $1.51-4.79$ & 0.001 \\
NYHA IV & 2.74 & $1.39-5.37$ & 0.003 \\
Insulin-treated diabetes & 2.65 & $1.50-4.68$ & 0.001 \\
Emergency operation & 3.39 & $1.40-8.24$ & 0.007 \\
Critical condition preoperatively & 7.49 & $2.19-25.7$ & 0.001
\end{tabular}

Due to a lack of aortic cross clamp time, patients undergoing off-pump CABG are not included in this model. *Multivariable backward stepwise logistic regression model. Nagelkerke $\mathrm{R}^{2}=0.322$; Hosmer-Lemeshow goodness-of-fit test $\mathrm{x}^{2}(\mathrm{df}=8)=7.280$, $\mathrm{p}=0.507$. Severe PHF, severe postoperative heart failure; CAD, coronary artery disease; CI, confidence interval; LV, left ventricular; NYHA, New York Heart Association.

\section{Preoperative NT-proBNP and postoperative mortality}

\section{(Paper I)}

Fifty-three (2\%) patients died postoperatively within 30 days or in-hospital; 40 due to PHF, 2 due to cardiac arrest and 9 due to non-cardiac causes (postoperative stroke $n=3$, infection $n=3$, primary renal failure $n=1$, respiratory cause $n=1$, intestinal ischemia $n=1$ ) whereas cause of death was unknown in 2 patients (Supplemental Table S3 of Paper I). Patients with postoperative mortality had significantly higher preoperative NT-proBNP than 
patients without postoperative mortality (1780 [430-3200] vs 320 [130958] ng $\left.\cdot \mathrm{L}^{-1}, \mathrm{p}<0.0001\right)$.

In CAD patients, preoperative NT-proBNP demonstrated significant discrimination with regard to postoperative mortality (AUC $=0.78,95 \% \mathrm{CI}$ $0.71-0.85, \mathrm{p}<0.0001$; best cutoff $905 \mathrm{ng} \cdot \mathrm{L}^{-1}$ with a sensitivity of $67 \%$ and specificity of $77 \%$; Figure 2). The number of events was too few to permit ROC analysis in patients with AS $(n=4)$ or MR $(n=6)$.

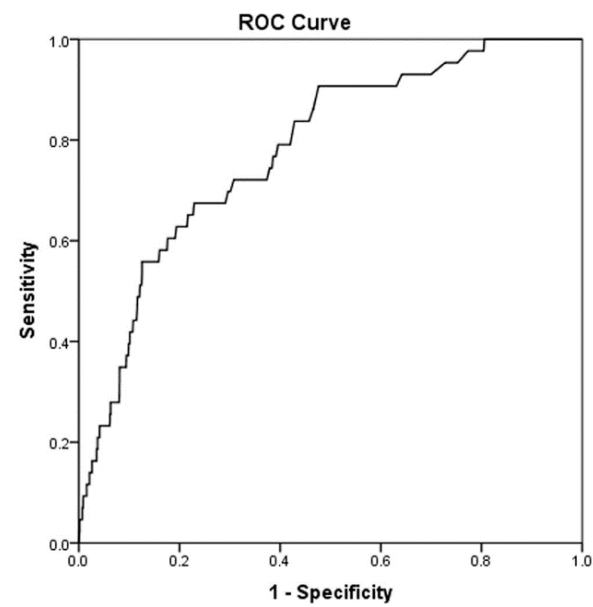

Figure 2. Discrimination of preoperative NT-proBNP with regard to postoperative mortality in patients with CAD. ROC analysis demonstrated an AUC of 0.78 (95\%CI $0.71-0.85, \mathrm{p}<0.0001$; best cutoff $905 \mathrm{ng} \cdot \mathrm{L}^{-1}$ with a sensitivity of $67 \%$ and specificity of $77 \%$ ). AUC, area under the curve; $\mathrm{CAD}$, coronary artery disease; $\mathrm{CI}$, confidence interval; ROC, receiver operating characteristics.

NT-proBNP $\geq 905 \mathrm{ng} \cdot \mathrm{L}^{-1}$ emerged as an independent risk factor for postoperative mortality in patients with CAD (adjusted OR 2.56, 95\% CI 1.21$5.40, p=0.014)$. Age, NYHA IV, preoperative albumin, preoperative dialysis, and emergency operation also remained in the final model for postoperative mortality (Table 5). 
Table 5. Multivariable analysis* of risk factors of postoperative mortality in CAD patients.

\begin{tabular}{llll}
\hline Variable & Odds ratio & $\mathbf{9 5 \% C I}$ & $\mathbf{p}$ \\
\hline Age (years) & 1.09 & $1.04-1.15$ & $<0.0001$ \\
NYHA IV & 2.84 & $1.23-6.56$ & 0.015 \\
Emergency operation & 3.54 & $1.29-9.68$ & 0.014 \\
Preop dialysis & 24.2 & $6.33-92.3$ & $<0.0001$ \\
Preop NT-proBNP $\geq 905 \mathrm{ng} \cdot \mathrm{L}^{-1}$ & 2.56 & $1.21-5.40$ & 0.014 \\
Preop p-albumin, $\mathrm{g} \cdot \mathrm{L}^{-1}$ & 0.93 & $0.86-0.99$ & 0.025 \\
\hline
\end{tabular}

*Multivariable backward stepwise logistic regression model. Nagelkerke $\mathrm{R}^{2}=0.254$; Hosmer-Lemeshow goodness-of-fit test $\mathrm{x}^{2}(\mathrm{df}=8)=6.560, \mathrm{p}=0.535$. CAD, coronary artery disease; CI, confidence interval; NYHA, New York Heart Association functional classification.

\section{NT-proBNP levels in relation to PHF in surgery for aor- tic stenosis (Paper II)}

Paper II was based on a cohort of 203 patients undergoing elective firsttime AVR for AS. NT-proBNP was sampled at the following time points: preoperative evaluation (PREEV) $(n=195)$, the day before the index procedure (PREOP) $(n=199)$, POD1 $(n=192)$, POD3 $(n=186)$, and at the sixmonth follow-up ( $\mathrm{n}=181)$.

Among all 203 patients, the median age was 70 [65-77] years and 50\% were female. The median EuroSCORE II was 1.6 [1.1-2.8]. More details are given in Table 1 Paper II.

Of the 18 patients who fulfilled study criteria for PHF, two had mild transient PHF that resolved without inotropes. Three patients developed severe PHF. No patient with PHF died within 30 days after surgery, but PHF was associated with a significantly longer ICU stay and ventilation time, more signs of myocardial injury, and renal dysfunction (Table 2 Paper II).

NT-proBNP level increased postoperatively in all patients, but this was significantly more pronounced on POD1 in patients with PHF vs. those with- 
out PHF (6415 [3145-11220] vs 2445 [1540-3855] ng. $\mathrm{L}^{-1}$, p<0.0001) (Figure 3). The average peak level was recorded on POD1 in the PHF cohort and on POD3 in the cohort without PHF. The NT-proBNP level on POD1 demonstrated good discrimination for PHF (AUC=0.82; 95\% CI 0.72-0.91; $\mathrm{p}<0.0001)$. The best cutoff value of $5290 \mathrm{ng} \cdot \mathrm{L}^{-1}$ had a sensitivity of $63 \%$ and a specificity of $85 \%$ (Figure 4). Poor discrimination was found preoperatively and later in the postoperative course (Figure 4).

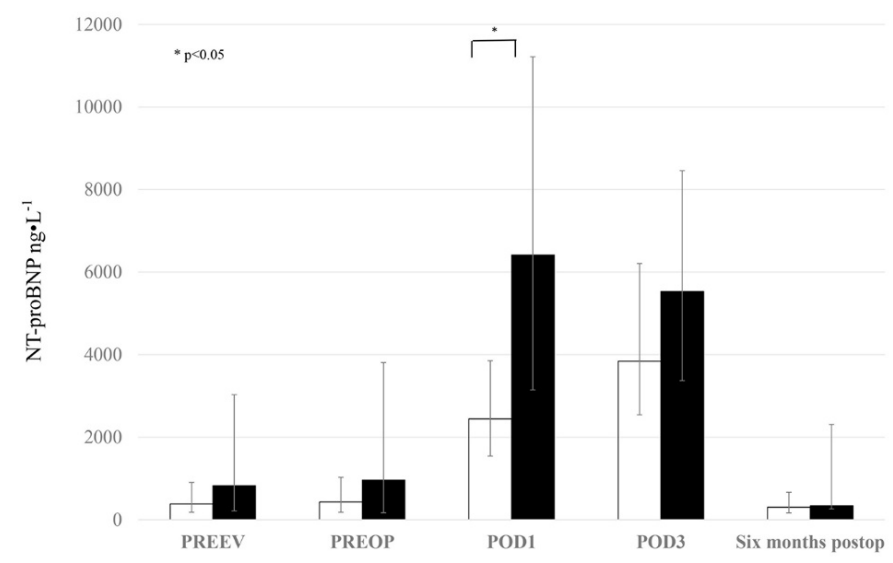

Figure 3. NT-proBNP levels before and after surgery in patients with PHF (black bars) and without PHF (white bars). PHF, postoperative heart failure; PREEV, preoperative evaluation; PREOP, the day before the index procedure; POD1, first postoperative day; POD3, third postoperative day; Six months postop, at the sixmonth follow-up. Data are expressed as medians with interquartile ranges; * $\mathrm{p}<0.05$.

NT-proBNP POD1 level $\geq 5290 \mathrm{ng} \cdot \mathrm{L}^{-1}$ emerged as a significant predictor of PHF together with p- CK-MB POD1 $>50 \mu \mathrm{g} \cdot \mathrm{L}^{-1}$ in the multivariable logistic regression model (Supplemental Table 2 of Paper II). Variables significantly associated with PHF in the univariable analysis are given in Supplemental Table 3 of Paper II. 


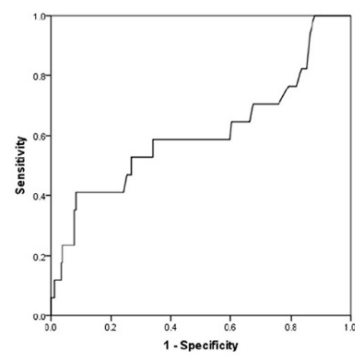

PREOP

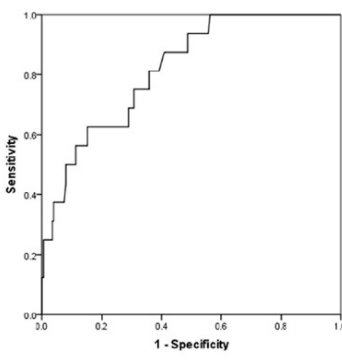

POD1

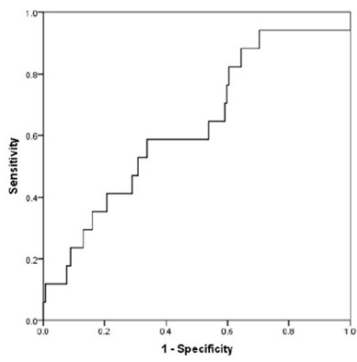

POD3

Figure 4. Discrimination of perioperative NT-proBNP for PHF in patients undergoing AVR for AS. According to receiver operating characteristic analyses, the NT-proBNP level on POD1 demonstrated good discrimination for PHF in patients undergoing AVR for AS (AUC $=0.82$; 95\%CI 0.72-0.91; $<<0.0001$; best cutoff $5290 \mathrm{ng} \cdot \mathrm{L}^{-1}$ with a sensitivity of $63 \%$ and a specificity of $85 \%$ ); whereas, the discrimination of NT-proBNP for PHF was less convincing on PREOP and POD3 (PREOP: AUC $=0.61,95 \% \mathrm{CI}$ 0.44-0.78, $\mathrm{p}=0.14$; POD3: $\mathrm{AUC}=0.63$, 95\% CI 0.49$0.77, \mathrm{p}=0.08)$. AS, aortic stenosis; AUC, area under the curve; AVR, aortic valve replacement; $\mathrm{CI}$, confidence interval; POD1, the first postoperative day; PHF, postoperative heart failure; POD3, the third postoperative day; PREOP, the day before the index procedure.

Patients with a NT-proBNP level $\geq 5290 \mathrm{ng} \cdot \mathrm{L}^{-1}$ on POD1 had a significantly longer ICU stay and more signs of myocardial and renal injury. None of these patients died within 30 days (Supplemental Table 4 of Paper II).

\section{NT-proBNP and PHF related to long-term survival af-}

\section{ter surgery for aortic stenosis (Paper II)}

The mean follow-up from the entry into the study was $8.9 \pm 1.1$ years (range 6.5-10.5 years). During this period, there were 48 deaths. Cumulative survival was significantly impaired in patients with PHF (Figure 5) and a NTproBNP level $\geq 5290 \mathrm{ng} \cdot \mathrm{L}^{-1}$ on POD1 (Figure 4 in Paper II). The cumulative survival in patients with PHF was impaired if the NT-proBNP level was $\geq 5290 \mathrm{ng} \cdot \mathrm{L}^{-1}$ on POD1 (Figure 6). The unadjusted hazard ratio (HR) for 
PHF for long-term mortality was 3.01 (95\%CI 1.45-6.21, $\mathrm{p}=0.003$ ). The unadjusted HR for patients with a NT-proBNP level $\geq 5290 \mathrm{ng} \cdot \mathrm{L}^{-1}$ on POD1 for long-term mortality was 3.25 (95\%CI 1.77-5.97, p<0.0001).

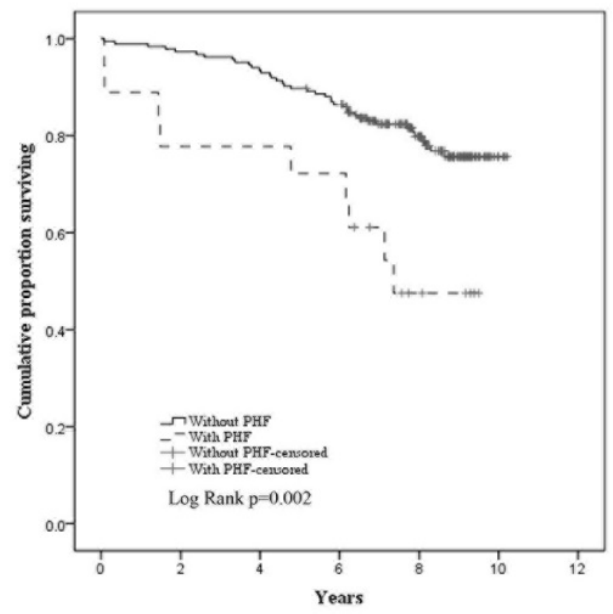

Patients at risk

\begin{tabular}{|l|l|l|l|l|l|l|l|l|l|l|l|}
\hline Year & 0 & 1 & 2 & 3 & 4 & 5 & 6 & 7 & 8 & 9 & 10 \\
\hline Without PHF & 185 & 183 & 180 & 178 & 173 & 166 & 159 & 123 & 89 & 43 & 3 \\
\hline PHF & 18 & 16 & 14 & 14 & 14 & 13 & 13 & 9 & 5 & 4 & \\
\hline
\end{tabular}

Figure 5. Cumulative survival (Kaplan-Meier) for patients with (dashed line) or without postoperative heart failure (PHF) (solid line).

In the multivariable Cox regression model PHF with a NT-proBNP level $\geq 5290 \mathrm{ng} \cdot \mathrm{L}^{-1}$ on POD1 emerged as a predictor of long-term mortality (HR 6.20, 95\%CI 2.72-14.12, $\mathrm{p}<0.0001)$ together with preoperative NTproBNP, age and diabetes mellitus (Table 6). The univariate hazard ratios of variables tested in the multivariable Cox regression are shown in Supplemental Table 5 of Paper II. 


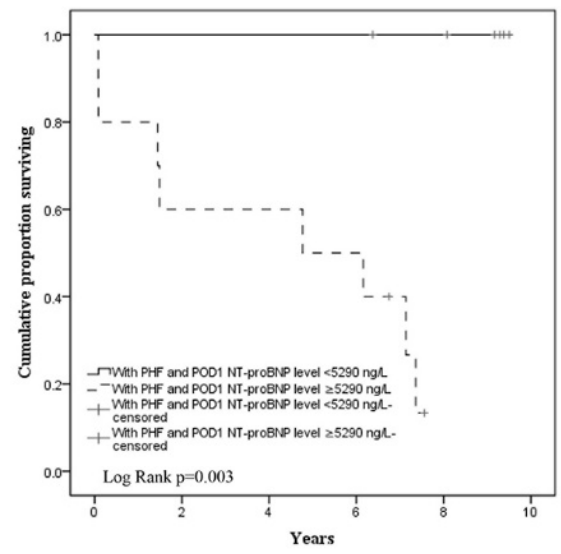

Patients at Risk

\begin{tabular}{|l|l|l|l|l|l|l|l|l|l|l|}
\hline Year & 0 & 1 & 2 & 3 & 4 & 5 & 6 & 7 & 8 & 9 \\
\hline PHF and POD1 NT-proBNP $<5290 \mathrm{ng} \cdot \mathrm{L}^{-1}$ & 6 & 6 & 6 & 6 & 6 & 6 & 6 & 5 & 5 & 4 \\
\hline PHF and POD1 NT-proBNP $\geq 5290 \mathrm{ng} \cdot \mathrm{L}^{-1}$ & 10 & 8 & 6 & 6 & 6 & 5 & 5 & 3 & & \\
\hline
\end{tabular}

Figure 6. Cumulative survival (Kaplan-Meier) in the subgroup with PHF for patients with a NT-proBNP level $\geq 5290 \mathrm{ng} \cdot \mathrm{L}^{-1}$ (dashed line) or $<5290 \mathrm{ng} \cdot \mathrm{L}^{-1}$ (solid line) on POD1. The NT-proBNP level on POD1 was missing in two patients (one died 6 years after surgery, the other one was alive 7 years after surgery). PHF, postoperative heart failure; POD1, the first postoperative day.

Table 6. Hazard Ratios for long-term mortality in patient undergoing AVR for AS in the multivariable regression model

\begin{tabular}{llll}
\hline Variable & Hazard Ratio & $\mathbf{9 5 \% C I}$ & p \\
\hline PHF with NT-proBNP POD1 $\geq 5290 \mathrm{ng} \cdot \mathrm{L}^{-1}$ & 6.20 & $2.72-14.1$ & $<0.0001$ \\
NT-proBNP PREOP $\geq 825 \mathrm{ng} \cdot \mathrm{L}^{-1^{*}}$ & 2.80 & $1.48-5.29$ & 0.002 \\
Age (years) & 1.07 & $1.02-1.11$ & 0.002 \\
Diabetes mellitus $^{\dagger}$ & 2.42 & $1.22-4.80$ & 0.011
\end{tabular}

* The best cutoff of preoperative NT-proBNP with regard to long-term mortality was 825 $\mathrm{ng} \cdot \mathrm{L}^{-1}\left(\mathrm{AUC}=0.73, \mathrm{p}<0.0001\right.$, with a sensitivity of $64 \%$ and specificity of $76 \%$ ). ${ }^{\dagger}$ Diabetes mellitus regardless of treatment. CI, confidence interval; POD1, first postoperative day; PREOP, the day before index procedure. 


\section{PHF and severe PHF in isolated CABG for ACS (Paper}

III)

Paper III was based on a cohort of 382 patients with ACS undergoing urgent isolated first-time CABG. NT-proBNP was available as follows: preoperative $(n=366)$, postoperative day $1(n=320)$ and postoperative day 3 $(n=325)$ and data from all three time points available in 267 patients. Among all 382 patients, the median age was 69 [62-75] years and $19 \%$ were female. The median EuroSCORE II was 2.4 [1.6-3.9]. More details showed in Table 1 in Paper III.

Overall 88 patients (23\%) were treated with inotropes at some stage intraoperatively or postoperatively (Supplemental Table S1 of Paper III). Only 33 of these patients fulfilled criteria for PHF and these patients had significantly worse outcome and more pronounced increase of NT-proBNP postoperatively (Supplemental Table S1 of Paper III).

Overall 35 patients (9\%) from the whole cohort fulfilled criteria for PHF. Seven of these patients were also classified to have severe PHF. Two patients had mild transient PHF that resolved without inotropes.

Patients with PHF had a more pronounced risk profile preoperatively and extended cross-clamp and CPB times intraoperatively. Postoperatively they had more signs of myocardial injury, higher incidence of acute kidney injury, extended ventilation time, prolonged ICU stay and a higher hospital mortality compared to those without PHF. Clinical outcomes were further aggravated in patients with severe PHF (Table 2 in Paper II). 


\section{Postoperative NT-proBNP in relation to PHF in iso- lated CABG for ACS (Paper III)}

Overall NT-proBNP increased from 420 [150-970] ng. $\mathrm{L}^{-1}$ preoperatively to 2065 [1324-365o] ng. $\mathrm{L}^{-1}(\mathrm{p}<0.001)$ POD1 and to 3610 [2167-6010] $\mathrm{ng} \cdot \mathrm{L}^{-1}$ ( $\mathrm{p}<0.001)$ POD3. Patients with PHF had higher pre- and postoperative levels of NT-proBNP compared to those without PHF (Figure 7).

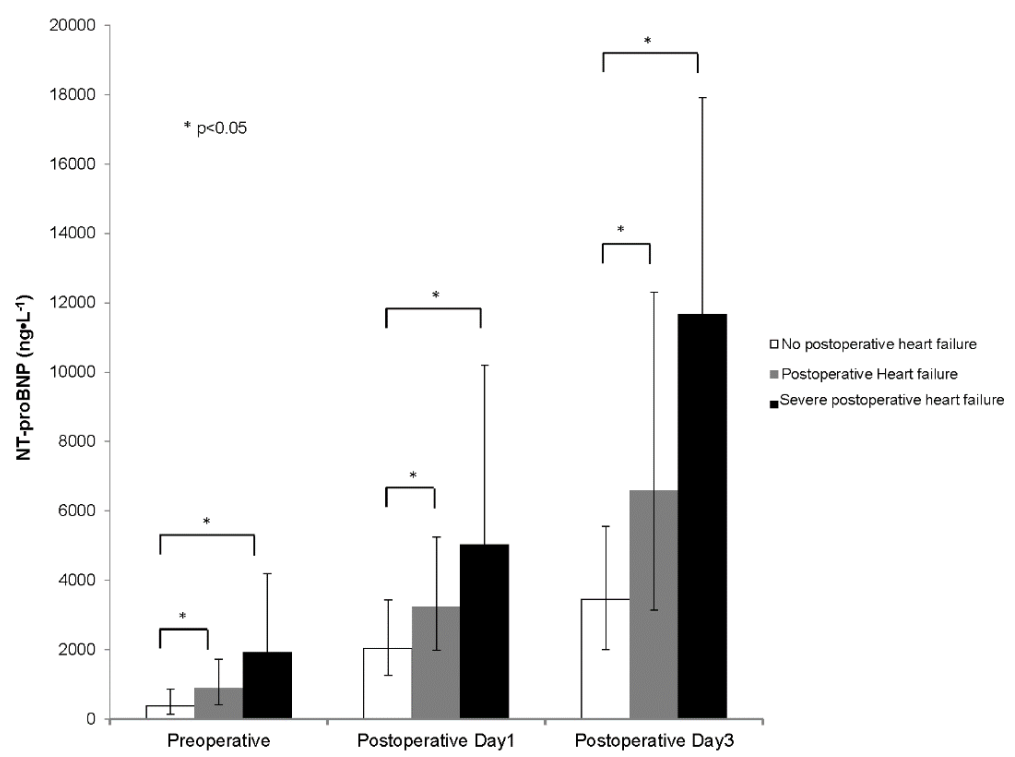

Figure 7. Perioperative NT-proBNP levels in patients without PHF, with PHF and severe PHF. Data given as medians with interquartile range. Mann-Whitney U test was performed and $p<0.05$ was considered significant, indicated by*. PHF, postoperative heart failure.

After adjusting for glutamate treatment and known preoperative non-cardiac confounders age, eGFR, female and obesity, NT-proBNP POD1 was 1.46 times higher in patients with PHF than in patients without PHF (ad- 
justed coefficient $0.164,95 \% \mathrm{CI}$ 0.064-0.265, $\mathrm{p}=0.001$; Table 7). Interaction of glutamate was not statistically significant and would have changed the adjusted coefficient for PHF by $3 \%$ if kept in the final model.

Table 7. Multivariable linear regression results for $\log _{10}$ NT-proBNP POD1 in all patients adjusted for PHF, glutamate treatment and known preoperative non-cardiac confounders*.

\begin{tabular}{lllc}
\hline Variable & Adjusted coefficient & $\mathbf{9 5 \% C I}$ & p \\
\hline PHF & 0.164 & $0.064-0.265$ & 0.001 \\
eGFR $\left(\mathrm{mL} \cdot \mathrm{min}^{-1} \cdot 1.73 \mathrm{~m}^{-2}\right)$ & -0.005 & $-0.006--0.003$ & $<0.0001$ \\
Female & 0.176 & $0.098-0.255$ & $<0.0001$ \\
\hline
\end{tabular}

*age, eGFR, female gender, obesity. Adjusted $\mathrm{R}^{2}=0.31$, ANOVA for the model $(\mathrm{df}=3$, $\mathrm{F}=46.48, \mathrm{p}<0.0001$ ). $\mathrm{CI}$, confidence interval; eGFR, estimated glomerular filtration rate according to MDRD formula; PHF, postoperative heart failure.

After similar adjustment for glutamate treatment and known preoperative non-cardiac confounders, NT-proBNP POD3 was 1.54 times higher in patients with PHF than in patients without PHF (adjusted coefficient 0.188, 95\%CI 0.188-0.289, p<0.0001; Table 8). Interaction of glutamate was not statistically significant and would not have changed the adjusted coefficient for PHF if kept in the final model.

Table 8. Multivariable linear regression results for $\log _{10}$ NT-proBNP POD 3 in all patients adjusted for PHF, glutamate treatment and known preoperative non-cardiac confounders*.

\begin{tabular}{llll}
\hline Variable & Adjusted coefficient & $\mathbf{9 5 \% C I}$ & $\mathbf{p}$ \\
\hline PHF & 0.188 & $0.088-0.289$ & $<0.0001$ \\
Age (years) & 0.011 & $0.007-0.016$ & $<0.0001$ \\
eGFR $\left(\mathrm{mL} \cdot \mathrm{min}^{-1} \cdot 1.73 \mathrm{~m}^{-2}\right)$ & -0.003 & $-0.005--0.002$ & $<0.0001$ \\
Female & 0.104 & $0.029-0.178$ & 0.006 \\
\hline
\end{tabular}

*age, eGFR, female gender, obesity. Adjusted $\mathrm{R}^{2}=0.39$, ANOVA for the model ( $\mathrm{df}=4$, $\mathrm{F}=50.26, \mathrm{p}<0.0001)$. CI, confidence interval; eGFR, estimated glomerular filtration rate according to MDRD formula; PHF, postoperative heart failure.

NT-proBNP on POD1 demonstrated significant discrimination for PHF (AUC=0.70; 95\%CI 0.61-0.79; $\mathrm{p}<0.0001$ ). The best cutoff value of 1836 
ng. $\mathrm{L}^{-1}$ had a sensitivity of $90 \%$ and a specificity of $46 \%$ (Figure $8 \mathrm{~A}$ ). A similar discrimination was found for NT-proBNP on POD3 (AUC $=0.70 ; 95 \%$ CI $0.60-0.81 ; \mathrm{p}<0.0001)$. The best cutoff value $6065 \mathrm{ng}^{\circ} \mathrm{L}^{-1}$ had a sensitivity of $57 \%$ and a specificity of $79 \%$ (Figure $8 \mathrm{~B}$ ).

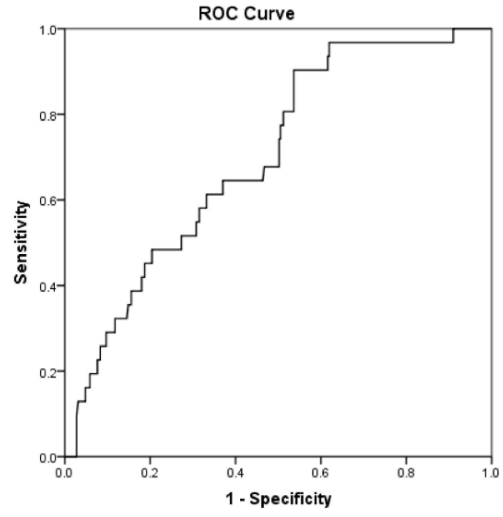

A

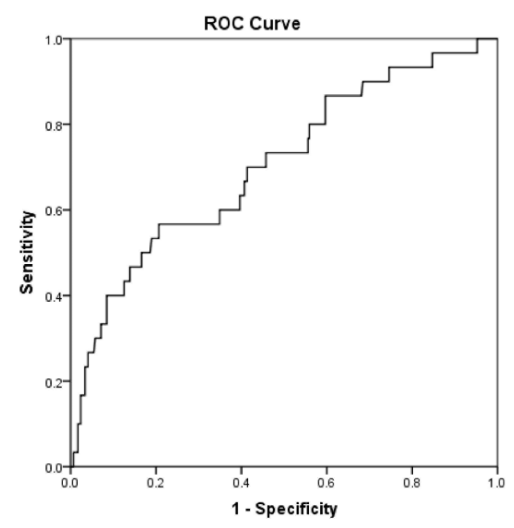

B

Figure 8. Receiver operating characteristics (ROC) to evaluate discrimination of postoperative NT-proBNP for PHF. Left panel (A) demonstrates discrimination of NT-proBNP on POD1 for PHF (AUC $=0.70 ; 95 \%$ CI 0.61-0.79; $p<0.0001$, best cutoff $1836 \mathrm{ng} \cdot \mathrm{L}^{-1}$ with a sensitivity of $90 \%$ and a specificity of $46 \%$ ). Right panel (B) demonstrates discrimination of NT-proBNP on POD3 for PHF (AUC $=0.70$; $95 \%$ CI $0.60-0.81 ; \mathrm{p}<0.0001$, best cutoff $6065 \mathrm{ng} \cdot \mathrm{L}^{-1}$ with a sensitivity of $57 \%$ and a specificity of $79 \%$ ). AUC, area under curve; CI, confidence interval; POD1, postoperative day $1 ;$ POD3, postoperative day 3.

\section{Postoperative changes of NT-proBNP in relation to}

\section{PHF in isolated CABG for ACS (Paper III)}

NT-proBNP increased postoperatively in all patients with the highest values recorded on POD3. The postoperative increase of NT-proBNP was significantly more pronounced in patients with PHF and the postoperative changes of NT-proBNP were associated with PHF.

Postoperative increase of NT-proBNP from preoperative level to POD3 demonstrated significant discrimination for PHF (AUC=0.68, 95\% CI 
0.56-0.79, $\mathrm{p}=0.002$, best cutoff $7639 \mathrm{ng} \cdot \mathrm{L}^{-1}$ with a sensitivity of $40 \%$ and a specificity of 92\%). Similar discrimination was found for postoperative change of NT-proBNP from preoperative level to POD1 (AUC=0.66, 95\% CI $0.56-0.76, \mathrm{p}=0.004$, best cutoff $1372 \mathrm{ng} \cdot \mathrm{L}^{-1}$ with a sensitivity of $87 \%$ and a specificity of $46 \%$ ) and for postoperative change of NT-proBNP from POD1 to POD3 (AUC=0.63; 95\% CI 0.50-0.76, $\mathrm{p}=0.028$, best cutoff 4299 ng. $\mathrm{L}^{-1}$ with a sensitivity of $38 \%$ and a specificity of $\left.90 \%\right)$.

In the multivariable logistic regression analysis, delta Troponin T POD3Pre, delta NT-proBNP POD3-POD1 $\geq 4299 \mathrm{ng} \cdot \mathrm{L}^{-1}$ and severe LV dysfunction emerged as independent risk factors for PHF (Table 9). The univariable Odds ratios for variables tested in are shown in Supplemental Table $\mathrm{S} 4$ of Paper III.

Table 9 Multivariable analysis* of risk factors for PHF

\begin{tabular}{llll}
\hline Variable & Odds ratio & $\mathbf{9 5 \% C I}$ & $\mathbf{p}$ \\
\hline Delta Troponin T POD3-Pre $\left(\mathrm{ng} \cdot \mathrm{L}^{-1}\right)$ & 1.001 & $1.000-1.002$ & 0.002 \\
Delta NT-proBNP POD3-POD1 $\geq 4299 \mathrm{ng} \cdot \mathrm{L}^{-1}$ & 5.12 & $1.86-14.10$ & 0.002 \\
Severe LV dysfunction & 12.77 & $2.76-58.99$ & 0.001 \\
\hline
\end{tabular}

*Multivariable backward stepwise logistic regression model. Nagelkerke $\mathrm{R}^{2}=0.28$; Hosmer-Lemeshow goodness-of-fit test $\mathrm{x}^{2}(\mathrm{df}=8)=5.74, \mathrm{p}=0.68$. CI: confidence interval.

\section{Postoperative NT-proBNP in relation to severe PHF in isolated CABG for ACS (Paper III)}

The highest pre- and postoperative NT-proBNP values were recorded in patients with severe PHF (Figure 7).

Patients with severe PHF had significantly higher NT-proBNP preoperatively (1920 [1030-4202] v 750 [300-1265] ng. $\left.\mathrm{L}^{-1}, \mathrm{p}=0.022\right)$ and on POD1 
(5040 [3060-10200] v 2740 [1875-4600] ng. $\cdot \mathrm{L}^{-1}, \mathrm{p}=0.028$ ) compared to patients with PHF that was not classified as severe.

After adjusting for glutamate treatment and known preoperative non-cardiac confounders age, eGFR, female and obesity, NT-proBNP POD1 was 2.18 times higher in patients with severe PHF than in patients without PHF (adjusted coefficient 0.339, 95\%CI 0.134-0.543, p=0.001; Table 10). Interaction of glutamate was not statistically significant and would have changed the adjusted coefficient for severe PHF by $6 \%$ if kept in the final model.

Table 10. Multivariable linear regression results for $\log _{10}$ NT-proBNP POD1 adjusted for severe PHF* $^{*}$, glutamate treatment and known preoperative non-cardiac confounders ${ }^{\dagger}$.

\begin{tabular}{lllc}
\hline Variable & Adjusted coefficient & $\mathbf{9 5 \% C I}$ & p \\
\hline Severe PHF* & 0.339 & $0.134-0.543$ & 0.001 \\
eGFR $\left(\mathrm{mL} \cdot \mathrm{min}^{-1} \cdot 1.73 \mathrm{~m}^{-2}\right)$ & -0.005 & $-0.006--0.003$ & $<0.0001$ \\
Female & 0.166 & $0.083-0.249$ & $<0.0001$ \\
\hline
\end{tabular}

*Patients with PHF that were not classified as severe excluded. ${ }^{\dagger}$ age, eGFR, female gender, obesity. Adjusted $\mathrm{R}^{2}=0.29$, ANOVA for the model $(\mathrm{df}=3, \mathrm{~F}=41.90, \mathrm{p}<0.0001)$. CI: confidence interval; eGFR: estimated glomerular filtration rate according to MDRD formula; PHF: postoperative heart failure.

After similar adjustment for glutamate treatment and known preoperative non-cardiac confounders, NT-proBNP POD3 was 1.81 times higher in patients with severe PHF than in patients without PHF (adjusted coefficient 0.258, 95\%CI 0.042-0.474, $\mathrm{p}=0.019$; Table 11). Interaction of glutamate was not statistically significant would have changed the adjusted coefficient for severe PHF by $0.3 \%$ if kept in the final model.

NT-proBNP on POD1 demonstrated significant discrimination for severe PHF (AUC=0.86; 95\% CI 0.76-0.95; $\mathrm{P}=0.001$ ). The best cutoff value of $4575 \mathrm{ng} \cdot \mathrm{L}^{-1}$ had a sensitivity of $71 \%$ and a specificity of $84 \%$. A similar discrimination was found for NT-proBNP on POD3 (AUC=0.79; 95\% CI 0.55 
-1.00; $\mathrm{P}=0.015)$. The best cutoff value of $6065 \mathrm{ng} \cdot \mathrm{L}^{-1}$ had a sensitivity of $83 \%$ and a specificity of $77 \%$.

Table 11. Multivariable linear regression results for $\log _{10}$ NT-proBNP POD3 adjusted for severe PHF* $^{*}$, glutamate treatment and known preoperative non-cardiac confounders ${ }^{\dagger}$.

\begin{tabular}{llll}
\hline Variable & Adjusted coefficient & $\mathbf{9 5 \% C I}$ & $\mathbf{p}$ \\
\hline Severe PHF* & 0.258 & $0.042-0.474$ & 0.019 \\
Age $($ years $)$ & 0.012 & $0.007-0.016$ & $<0.0001$ \\
eGFR $\left(\mathrm{mL} \cdot \mathrm{min}^{-1} \cdot 1.73 \mathrm{~m}^{-2}\right)$ & -0.003 & $-0.004--0.002$ & $<0.0001$ \\
Female & 0.103 & $0.026-0.180$ & 0.009 \\
\hline
\end{tabular}

* Patients with PHF that were not classified as severe were excluded ${ }^{\dagger}$ age, eGFR, female gender, obesity. Adjusted $\mathrm{R}^{2}=0.35$, ANOVA for the model $(\mathrm{df}=4, \mathrm{~F}=41.84, \mathrm{p}<0.0001)$ $\mathrm{CI}$, confidence interval; eGFR, estimated glomerular filtration rate according to MDRD formula; PHF, postoperative heart failure.

Patients with NT-proBNP above the cutoffs had more pronounced Troponin $\mathrm{T}$ elevations, higher incidence of acute kidney injury, extended ventilation time, prolonged ICU stay and higher hospital mortality (Details are given in Supplemental Table S7 and S8 of Paper III).

\section{Influence of glutamate on postoperative NT-proBNP}

\section{in patients undergoing CABG for ACS (Paper IV)}

Paper IV was based on a cohort of 399 patients (glutamate group $n=199$, control group $n=200$ ) patients undergoing CABG for acute coronary syndrome. NT-proBNP measurements were available as follows: preoperative $(\mathrm{n}=383)$, postoperative day $1(\mathrm{n}=334)$ and postoperative day $3(\mathrm{n}=339)$. A complete set of NT-proBNP data was available in 280 patients. In 17 patients CABG with a concomitant procedure was done (mitral valve surgery $n=8$, aortic valve surgery $n=7$, and ablation for atrial fibrillation $n=2$ ). The median age was 69 [63-75] years and $19 \%$ were female. The median EuroSCORE II was 2.44 [1.65-4.15]. PHF developed in 40 patients and 10 of 
these developed severe PHF. Preoperative, intraoperative and postoperative data did not differ significantly between the glutamate group and the control group (Details showed in Table 1 and 2 in Paper IV).

In the whole cohort, postoperative NT-proBNP levels did not differ significantly between the glutamate group and the control group (POD1: 2220 [1484-4040] vs 2041 [1236-3429] ng. $\mathrm{L}^{-1}, \mathrm{p}=0.18$; POD3: 3640 [2335-6155] vs 3781 [2081-6020] $\left.\mathrm{ng} \cdot \mathrm{L}^{-1}, \mathrm{p}=0.95\right)$.

\section{Influence of glutamate on postoperative NT-proBNP in high risk patients undergoing CABG for ACS (Paper}

\section{IV)}

Post hoc analysis was done on 101 patients in the upper quartile of risk according to preoperative EuroSCORE II $\geq 4.15$ (glutamate group $n=56$; control group $n=45$ ). The groups were evenly distributed, with the exception of higher preoperative Troponin $\mathrm{T}$ (40 [0-39o] vs o [0-30] $\mathrm{ng} \cdot \mathrm{L}^{-1}$, $\mathrm{p}<0.0001)$ and more patients with angina at rest less than 48 hours before surgery (36\% vs 13\%, $\mathrm{p}=0.007$ ) in the control group (Table 12).

In the glutamate group patients had significantly lower postoperative increase of NT-proBNP (POD3-Pre: 390o [2995-6260] vs 6745 [3455-12687] $\mathrm{ng} \cdot \mathrm{L}^{-1}, \mathrm{p}=0.012$, ) and lower absolute levels of NT-proBNP POD3 compared to the control group (POD3: 4845 [3426-7423] vs 8430 [5370-1410o] ng. L${ }^{1}, \mathrm{p}=0.001$ ) (Figure 9). After adjusting for preoperative Troponin $\mathrm{T}$ and incidence of angina at rest less than 48 hours before surgery, only glutamate remained in the final multivariable linear regression model with regard to $\log _{10}$ NT-proBNP POD3. NT-proBNP POD3 in the glutamate group was 0.62 times of that in the control group (adjusted coefficient -0.208, 95\% CI -0.336- -0.080; $\mathrm{p}=0.002$ ). 
Table 12. Preoperative characteristics in patients with EuroSCORE II $\geq 4.15$.

\begin{tabular}{lcccc}
\hline Variables & $\begin{array}{c}\text { EuroSCORE II } \geq \mathbf{4 . 1 5} \\
(\mathbf{n = 1 0 1})\end{array}$ & $\begin{array}{c}\text { Glutamate } \\
(\mathbf{n}=\mathbf{5 6})\end{array}$ & $\begin{array}{c}\text { Control } \\
(\mathbf{n = 4 5})\end{array}$ & $\mathbf{p}$ \\
\hline Age (years) & $76[71-79]$ & $76[70-79]$ & $76[72-79]$ & 0.85 \\
Female gender & $38 \%(38)$ & $32 \%(18)$ & $44 \%(20)$ & 0.22 \\
BMI $\left(\mathrm{kg} \cdot \mathrm{m}^{-2}\right)$ & $25[22-28]$ & $25[22-28]$ & $26[23-28]$ & 0.64 \\
EuroSCORE II & $5.83[4.89-7.85]$ & $5.86[5.00-7.54]$ & $5.83[4.54-8.97]$ & 0.82 \\
Diabetes & $29 \%(29)$ & $27 \%(14)$ & $33 \%(15)$ & 0.38 \\
Hypertension & $72 \%(72)$ & $68 \%(38)$ & $76 \%(34)$ & 0.50 \\
COPD & $18 \%(18)$ & $21 \%(12)$ & $13 \%(6)$ & 0.31 \\
NT-proBNP $\left(\mathrm{ng} \cdot \mathrm{L}^{-1}\right)$ & $1010[450-2345]$ & $790[425-1895]$ & $1265[465-2915]$ & 0.15 \\
Hemoglobin $\left(\mathrm{g} \cdot \mathrm{L}^{-1}\right)$ & $132[121-142]$ & $133[125-143]$ & $130[115-139]$ & 0.08 \\
Troponin T $\left(\mathrm{ng} \cdot \mathrm{L}^{-1}\right)$ & $10[0-90]$ & $0[0-30]$ & $40[0-390]$ & $<0.0001$ \\
p-Creatinine $\left(\right.$ umol $\left.\cdot \mathrm{L}^{-1}\right)$ & $97[88-122]$ & $97[87-115]$ & $97[90-123]$ & 0.51 \\
eGFR (mL·min $\left.{ }^{-1} \cdot 1.73 \mathrm{~m}^{-2}\right)$ & $50[41-68]$ & $50[44-72]$ & $51[38-66]$ & 0.38 \\
Cerebrovascular disease & $21 \%(21)$ & $20 \%(11)$ & $23 \%(10)$ & 0.81 \\
Three-vessel disease & $83 \%(83)$ & $82 \%(46)$ & $82 \%(37)$ & 1.00 \\
Left main stenosis & $48 \%(48)$ & $45 \%(25)$ & $51 \%(23)$ & 0.55 \\
AMI $<3$ weeks & $73 \%(73)$ & $73 \%(41)$ & $71 \%(32)$ & 0.83 \\
History of AMI & $82 \%(82)$ & $82 \%(46)$ & $80 \%(36)$ & 0.80 \\
CCS IV & $80 \%(80)$ & $82 \%(46)$ & $76 \%(34)$ & 0.47 \\
Angina at rest $<48 \mathrm{~h}$ & $23 \%(23)$ & $13 \%(7)$ & $36 \%(16)$ & 0.007 \\
Moderate LV dysfunction & $21 \%(21)$ & $23 \%(13)$ & $18 \%(8)$ & 0.62 \\
Severe LV dysfunction & $14 \%(14)$ & $9 \%(5)$ & $20 \%(9)$ & 0.15 \\
\hline
\end{tabular}

Data given as medians [interquartile range] or percentages (number).

AMI $<3$ weeks, acute myocardial infarction within 3 weeks of surgery; Angina at rest $<$ 48h, angina at rest within 48 hours before surgery; BMI, body mass index; CCS, Canadian cardiovascular society; COPD, chronic obstructive pulmonary disease; EuroSCORE II, European system for cardiac operative risk evaluation II; LV, left ventricular; eGFR, estimated glomerular filtration rate according to MDRD formula. 


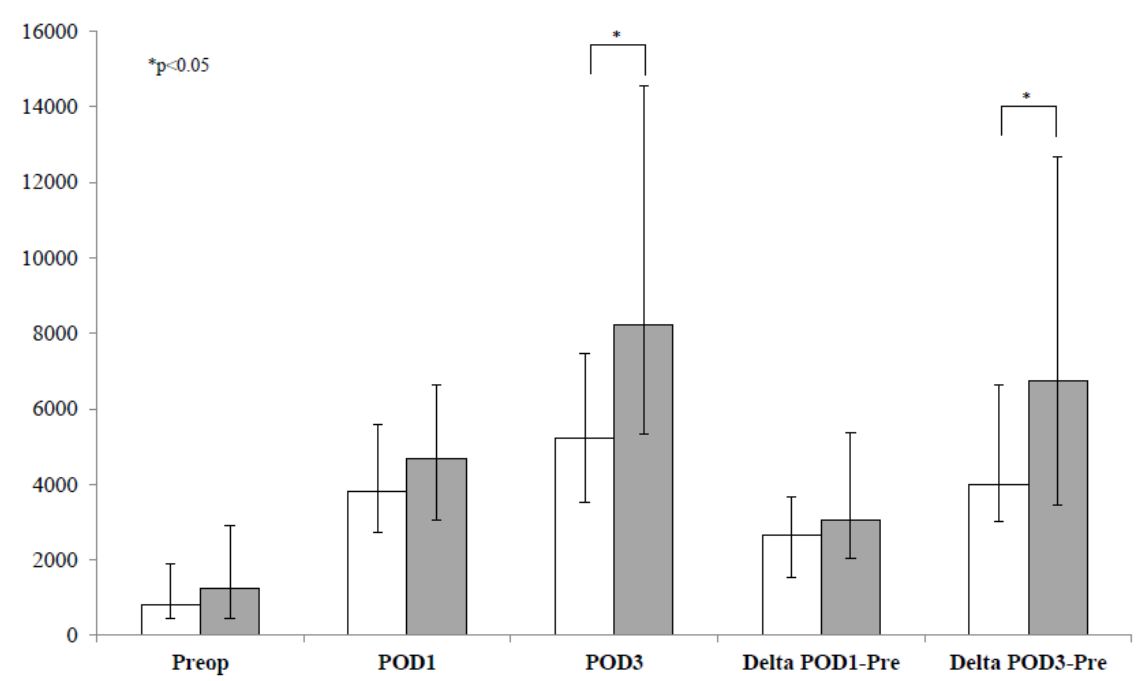

Figure 9. Perioperative NT-proBNP levels in patients with EuroSCORE II $\geq 4.15$ (upper quartile). White bars, glutamate group; grey bars, control group. Data expressed as medians with interquartile range. $* \mathrm{p}<0.05$. POD, postoperative day; Preop, preoperative.

Postoperatively patients in the glutamate group had less signs of myocardial injury (Troponin T POD3: 290 [160-480] vs 550 [210-860] ng. $\mathrm{L}^{-1}$, $\mathrm{p}=0.015$ ), shorter ICU stay (21 [19-26] vs 25 [22-45] hours, $\mathrm{p}=0.022)$ and a trend towards lower incidence of PHF ( $14 \%, n=8$ vs 31\%, $n=14, p=0.053$ ) and severe PHF ( $4 \%, n=2$ vs $16 \%, n=7, p=0.074$ ) (Table 4 in Paper IV). 


\section{DISCUSSION}

PHF remains the major cause of mortality after cardiac surgery ${ }^{1-6}$. Given the profound prognostic implications of PHF, it is unfortunate that universally accepted diagnostic criteria of PHF are lacking. NT-proBNP is an established biomarker for heart failure in cardiology practice 42, 43. However, the literature on the association between postoperative NT-proBNP and PHF after cardiac surgery provides little evidence.

Infusion of glutamate after coronary surgery has been reported to enhance both metabolic and hemodynamic myocardial recovery ${ }^{100,101}$. The aim of this dissertation has been to study the role of NT-proBNP for prediction and assessment of PHF in cardiac surgery and the impact of intravenous glutamate infusion on postoperative NT-proBNP after CABG.

\section{PHF after cardiac surgery}

As mentioned in the introduction PHF is associated with increased postoperative morbidity and mortality after cardiac surgery $1,3,10,106$. Our current studies found that hospital mortality of patients with PHF was 9-fold higher than in those without PHF after isolated CABG (Paper III). In contrast, none of the patients with PHF died early after AVR for AS but this was followed by poor long-term survival (Paper II). These results corroborate our previous observations, which showed that postoperative mortality associated with PHF after AVR for AS is low compared with PHF after CABG 7. Accordingly they also show that the serious consequences of PHF after AVR for AS become evident with time 7. A plausible explanation for the high early mortality associated with PHF in CABG is the strong association between PHF and myocardial ischemia during the early stages of surgery and perioperative myocardial infarction ${ }^{10}$. In AVR for AS only a small 
proportion of PHF cases are explained by perioperative myocardial infarction ${ }^{10}$. Although other potential causes such as preoperative left ventricular dysfunction, long aortic cross clamp time and septicemia can be identified a large proportion remains unexplained 6,10. A myocardial factor not yet evident at preoperative evaluation, unmasked by PHF, possibly associated with myocardial fibrosis and diastolic function has been suggested to be responsible for the poor long-term outcome in these patients after AVR for AS 7.

In contrast to our findings, Maganti et al reported that low cardiac output syndrome after AVR was associated with a high early mortality4. However, they studied all aortic valve procedures including a high proportion of reoperations, emergency procedures, and endocarditis with shock and renal dysfunction preoperatively presenting as important risk factors, which could explain the differences in early outcome 4.

Given the profound consequences of PHF it is a concern that generally accepted criteria for PHF are lacking. Consequently, it is unavoidably questionable whether the criteria used for the diagnosis of PHF in our studies were accurate.

PHF can be regarded as a hemodynamic state when cardiac output fails to meet the systemic demand without supportive measures other than correction of volume or vascular resistance. However, a low cardiac output does not necessarily imply PHF since the need for oxygen delivery can low in anesthetized patients early after cardiac surgery ${ }^{15}$. We defined PHF by use of $\mathrm{SvO}_{2}$, which can detect a mismatch of oxygen delivery and systemic oxygen demand ${ }^{16-18}$. $\mathrm{SvO}_{2}$ is well documented with regard to outcome after cardiac surgery ${ }^{16-18}$. Furthermore, well-known pitfalls such as hypovolemia, anemia and shivering were taken into account by the Clinical endpoints committee ${ }^{15}$. 
Reliance on treatment criteria for diagnosis of PHF, such as inotrope requirements or need for mechanical cardiac assist device are clouded by the large differences between geographical regions, institutions and individuals regarding threshold for institution of treatment or prophylaxis ${ }^{12,20}$. The attending anesthesiologist, independently of the patient, has been shown to be a strong predictor for instituting inotropic treatment ${ }^{107}$.

Our studies revealed that patients classified as PHF had more adverse outcome than those treated with inotropes who did not fulfil criteria for PHF (Paper II and III). These results suggest that the sickest patients were identified by the blinded endpoints committee using our prespecified criteria (Supplemental Table 3 of Paper II).

\section{NT-proBNP in cardiac surgery}

\section{The impact of underlying heart disease on preoperative NT- proBNP}

The role of underlying heart disease was studied in Paper I. Among patients with $\mathrm{CAD}, \mathrm{AS}$ and $\mathrm{MR}$, the cohort with $\mathrm{AS}$ had the highest level of preoperative NT-proBNP, whereas patients with CAD had the lowest values. These findings are consistent with previous studies 44-46, 64, 67, 78, 108, 109 .

In the setting of volume expansion, pressure overload or ischemia, the resulting ventricular wall stress causes release of natriuretic peptides from the myocardium ${ }^{27,110}$. However, renal dysfunction, advanced age and female gender are associated with increased natriuretic peptide levels, regardless of left ventricular systolic function, whereas obesity has an inverse relationship with natriuretic peptide levels $30,47,48,111$. As all of these demographics with the exception of eGFR differed between the studied co- 
horts we believe it was important to adjust for these non-cardiac confounders to evaluate the role of underlying heart disease per se. After adjusting for these non-cardiac confounders, we found that AS and MR patients still had higher NT-proBNP levels than CAD patients.

The results suggest that stimuli for release of natriuretic peptides by ventricular wall stress caused by pressure overload or volume overload are more important than ischemia per se. However, ischemia is a well-recognized stimulus for the release of natriuretic peptides, though it is unclear to what extent this is caused by myocardial stunning or ischemia per se ${ }^{29}$. Increasing clinical severity and extent of CAD is associated with higher levels of natriuretic peptides even in the absence of LV dysfunction 112-114. Even within the "normal range of NT-proBNP" patients with CAD have higher levels than those without $\mathrm{CAD}^{112}$.

The association between valvular heart disease and natriuretic peptides has received more attention, as echocardiographic findings are easier to link with natriuretic peptide levels. In MR patients, BNP reflects the hemodynamic consequences of MR, and preserved LVEF, left atrial volume and longitudinal myocardial function are the main determinants of BNP levels 28, 115. Similarly in AS patients with preserved LVEF, BNP levels reflect the clinical and echocardiographic consequences of the afterload burden on the left ventricle rather than the severity of aortic stenosis per se ${ }^{116}$.

\section{Preoperative NT-proBNP in cardiac surgery}

Regarding the prognostic value of natriuretic peptides, high levels of these biomarkers have been reported to be associated with postoperative mortality, in-hospital cardiac events, need for inotropic support, and PHF after cardiac surgery $53,55,56,65,66$. The prognostic value of NT-proBNP with regard to PHF and short-term or long-term mortality in different patient cohort will be discussed in the forthcoming sections. 


\section{Preoperative NT-proBNP and postoperative heart failure}

In Paper I, the discrimination of preoperative NT-proBNP with regard to severe PHF was good in CAD and MR patients. In CAD patients, NTproBNP also emerged an independent risk factor for severe PHF.

The predictive value of preoperative NT-proBNP with regard to severe PHF was less convincing in patients operated for AS. Similar results in AS patients were found in the prospective study (Paper II) relying on prespecified criteria for PHF. A plausible explanation is that a sizeable proportion of PHF after AVR for AS occurs unexpectedly because of intraoperatively acquired myocardial dysfunction in patients preoperatively considered to carry a low risk 6 .

Weber et al. reported similar results evaluating the prognostic value of baseline NT-proBNP with regard to adverse outcome consisting of cardiac death and or rehospitalization for heart failure during follow-up in patients with AS being treated conservatively or undergoing AVR ${ }^{117}$. Preoperative NT-proBNP independently predicted adverse outcome in conservatively treated patients but not in patients undergoing AVR ${ }^{117}$.

These findings differ from a study, which reports preoperative BNP to accurately predict MACEs after AVR but not after CABG44. However, in that study MACEs were defined as one of following: cardiac dysfunction, Qwave infarction, malignant ventricular arrhythmias, and repeat revascularization, during the first 12 months after surgery.

\section{Preoperative NT-proBNP and mortality after cardiac surgery}

Paper I showed a best cutoff preoperative NT-proBNP of $905 \mathrm{ng} \cdot \mathrm{L}^{-1}$ with regard to postoperative mortality in patients with $\mathrm{CAD}$. This finding corroborates the results of a prospective study by Holm et al. from our institu- 
tion on a smaller sample $(n=366)$ undergoing isolated CABG for acute coronary syndrome. They reported preoperative NT-proBNP $\geq 1028 \mathrm{ng} \cdot \mathrm{L}^{-1}$ to be a strong predictor for in-hospital mortality 65.

There were too few events in AS and MR patients to conduct meaningful analyses with regard to postoperative mortality.

In a multivariable regression model regarding long-term mortality in patients undergoing AVR for AS, preoperative NT-proBNP $\geq 825 \mathrm{ng} \cdot \mathrm{L}^{-1}$ emerged as an independent risk factor (Paper II). This result supports the theory about an underlying myocardial factor as a cause of the increased late mortality, but the proposed role of diastolic dysfunction for long-term outcome after AVR for AS remains disputable and requires further investigation ${ }^{118}$.

\section{Postoperative NT-proBNP and postoperative heart failure}

Although previous studies suggest an association between postoperative levels of natriuretic peptides and PHF only half a dozen studies have evaluated postoperative natriuretic peptides with regard to what could be considered PHF 2, 51, 55, 71, 75, 76. Only two of them included more than one hundred patients but both used treatment criteria for PHF 2, 55. Three studies used prespecified criteria but they were small and PHF accounted only for a proportion of postoperative complications that constituted the endpoint $51,75,76,100$.

We found that postoperative NT-proBNP displayed good discrimination for PHF in patients undergoing AVR for AS and isolated CABG respectively. Patients with postoperative NT-proBNP above the best cutoff had adverse short-term outcome. To our knowledge this is the first time when a blinded assessment of postoperative NT-proBNP with regard to PHF was done in 
prospective studies relying on prespecified hemodynamic criteria. Our results agree with the finding of other studies, in which high postoperative levels of natriuretic peptides have been reported to be linked with adverse outcome, need for inotropic and mechanical circulatory support and oneyear mortality $2,51,55,71,73-76,119$.

In patients undergoing isolated CABG, postoperative NT-proBNP demonstrated significant discrimination for PHF and particularly severe PHF (Paper III). Given that the group with PHF included some mild cases of heart failure it is not surprising that the discrimination of NT-proBNP was more evident with regard to severe PHF. NT-proBNP levels were higher in patients with severe PHF, which is expected given that the release of B-type natriuretic peptide into the circulation is proportional to the ventricular expansion and volume overload ${ }^{24,} 27$.

Multivariable analysis identified preoperative left ventricular dysfunction, intraoperative myocardial injury and postoperative increase of NT-proBNP to be associated with PHF. The elevated postoperative levels of NT-proBNP were caused by higher plasma concentrations preoperatively and more pronounced increases postoperatively. Postoperative NT-proBNP, thus, reflected the preoperative condition of the heart as well as myocardial dysfunction sustained during and after surgery. This agrees with the literature, which reports preoperative left ventricular dysfunction and perioperative myocardial infarction to be important causes for PHF in patients undergoing $\mathrm{CABG}{ }^{8,10}$.

The cutoff levels of NT-proBNP for PHF and severe PHF in particular after CABG should be interpreted with caution because of the low number of events. 
In contrast to what was found in CABG, only NT-proBNP level on POD1 provided good discrimination for PHF in patients undergoing AVR for AS (Paper II). Nozohoor et al. reported that high BNP level on admission to the ICU was an independent predictor of PHF after AVR². The early postoperative natriuretic peptides thus appear to reflect the preoperative cardiac function and myocardial dysfunction sustained during the operation. However, we have no certain explanation to the indecisive results on POD3, but this could be related to the low number of events.

The current results also show that a NT-proBNP level $\geq 5290 \mathrm{ng} \cdot \mathrm{L}^{-1}$ on POD1 can help identify which PHF patients after AVR for AS carry a markedly increased risk of poor long-term survival and, hence, may require increased postoperative surveillance.

\section{The impact of glutamate on postoperative NT-proBNP}

In high-risk patients post hoc analyses, even after adjustment for significant differences in preoperative demographics, demonstrated that intravenous glutamate infusion was associated with mitigated postoperative increase of NT-proBNP resulting in substantially lower NT-proBNP levels on POD3 compared to controls. Based on available knowledge about myocardial metabolism it is conceivable that glutamate influenced postoperative NT-proBNP levels by promoting post-ischemic recovery of myocardial oxidative metabolism. Further studies are necessary to confirm these findings.

As explained in the introduction, the biochemical properties of glutamate could increase myocardial tolerance to ischemia and enhance myocardial recovery after ischemia ${ }^{89,90,92}$. Glutamate's effect is dependent on whether there is a metabolic derangement which glutamate can facilitate the recovery of $92,100,120$. As might be expected such an effect could not be detected 
in low-risk patients with no or minimal metabolic derangement ${ }^{121}$. In the GLUTAMICS-trial, a high proportion of low-risk patients were included ${ }^{102}$.

Glutamate administration contributes little to these patients as the high myocardial extraction rate of glutamate from blood seen normally early after CABG is sufficient for recovery of myocardial metabolism in most of these patients 95 . This might explain why we were unable to detect an impact of glutamate on postoperative NT-proBNP in the whole cohort.

\section{Clinical implications}

Our studies confirm the value of preoperative NT-proBNP for predicting operative risk in patients admitted for cardiac surgery. The underlying heart disease has to be taken into account as patients with AS or MR have higher preoperative NT-proBNP than CAD patients undergoing first time cardiac surgery.

Neither echocardiography nor pulmonary artery catheters may be appropriate for diagnosis of PHF in large clinical trials due to the investigator dependence of transesophageal echocardiography and rare routine use of pulmonary artery catheters, although these methods undoubtedly provide important information in the diagnosis of PHF and its treatment. In contrast, a readily accessible and inexpensive option for objective assessment of $\mathrm{PHF}$ is provided by natriuretic peptides in clinical trials.

In coronary surgery our results suggest that postoperative NT-proBNP adds an unbiased dimension to the evaluation of PHF and its severity and, hence, can be used as marker of PHF after CABG. This is important since the lack of generally accepted criteria for PHF may partly explain the limited number of trials and the poor evidence for current treatment of the condition responsible for the majority of postoperative deaths. 
In AVR for AS our results and a previous study suggest that postoperative natriuretic peptides obtained on POD1 or earlier in the postoperative course can be used as markers of $\mathrm{PHF}^{2}$. This is particularly important as assessment of the efficacy of treatment and prophylaxis may require several years of follow-up due to the delayed prognostic consequences of PHF after AVR for AS.

In clinical practice NT-proBNP level $\geq 5290 \mathrm{ng} \cdot \mathrm{L}^{-1}$ on POD1 can be useful for recognizing patients with an episode of PHF after AVR for AS who are at risk of poor long-term survival and therefore require increased postoperative surveillance. This is advisable since the delayed consequences of PHF after AVR for AS have been reported to be equally profound in patients considered to be low-risk preoperatively ${ }^{122}$.

The finding that glutamate might have an impact on postoperative NTproBNP levels in high-risk patients undergoing CABG is encouraging and in line with previous metabolic and hemodynamic studies after CABG ${ }^{100}$, 123. The post hoc results, however, need to be confirmed in future prospective clinical trials on high-risk patients before this treatment can be recommended for general use.

\section{Future Research}

We suggest that future studies on preoperative natriuretic peptides should address if they can be incorporated into available risk scores to improve the prognostic value of risk scores such as EuroSCORE II. Also, it could be worthwhile to study if preoperative natriuretic peptides can be used as a tool for preoperative optimization of high-risk patients.

Increase of postoperative natriuretic peptides can be used to evaluate treatment of PHF in future studies. As we found that postoperative trends of 
NT-proBNP were of prognostic importance we also suggest that future studies should address if natriuretic peptides can be used for design of goal directed therapy. Furthermore, the role of natriuretic peptides for postoperative surveillance during follow-up after surgery deserves further attention.

The encouraging results regarding the effect of intravenous glutamate infusion on postoperative NT-proBNP levels in association with CABG on high-risk patients has already stimulated the initiation of the ongoing GLUTAMICSII trial (ClinicalTrials.gov Identifier: NCTo2592824). 


\section{CONCLUSIONS}

- Patients with AS or MR admitted for first time cardiac surgery had higher preoperative NT-proBNP than CAD patients, even after adjusting for non-cardiac confounders.

- The predictive value of preoperative NT-proBNP with regard to severe PHF was good in CAD and MR patients admitted for surgery, but less convincing in AS patients.

- The predictive value of preoperative NT-proBNP with regard to postoperative mortality was confirmed in patients operated for CAD. The number of events was too few to permit analysis in patients operated for AS or MR.

- The predictive value of preoperative NT-proBNP with regard to longterm survival was confirmed in patients undergoing elective AVR for AS.

- NT-proBNP on POD1 provided good discrimination of PHF in patients undergoing elective AVR for AS.

- PHF after elective AVR for AS was associated with a poor long-term survival, although it initially appeared benign. NT-proBNP $\geq 5290$ $\mathrm{ng} \bullet \mathrm{L}^{-1}$ on POD1 identified which patients with PHF had an increased risk of poor long-term survival.

- The absolute postoperative levels and postoperative changes of NTproBNP were associated with PHF after isolated CABG for acute coronary syndrome. The postoperative levels levels reflected the severity of PHF.

- Intravenous infusion of glutamate in patients undergoing CABG for ac ute coronary syndrome:

- in the majority of patients glutamate did not affect the postoperative NT-proBNP levels 
- in high-risk patients glutamate (EuroSCOREII $\geq 4.15$ ) was associated with reduced increase of NT-proBNP and lower postoperative levels of NT-proBNP

- further studies are necessary to confirm these post-hoc findings 


\section{REFERENCES}

1. O'Connor GT, Birkmeyer JD, Dacey LJ, Quinton HB, Marrin CA, Birkmeyer NJ, et al. Results of a regional study of modes of death associated with coronary artery bypass grafting. Northern New England Cardiovascular Disease Study Group. Annals of Thoracic Surgery. 1998;66:1323-8.

2. Nozohoor S, Nilsson J, Luhrs C, Roijer A, Algotsson L, Sjogren J. B-type natriuretic peptide as a predictor of postoperative heart failure after aortic valve replacement. Journal of Cardiothoracic and Vascular Anesthesia. 2009;23:161-5.

3. Rao V, Ivanov J, Weisel RD, Ikonomidis JS, Christakis GT, David TE. Predictors of low cardiac output syndrome after coronary artery bypass. Journal of Thoracic and Cardiovascular Surgery. 1996;112:38-51.

4. Maganti MD, Rao V, Borger MA, Ivanov J, David TE. Predictors of low cardiac output syndrome after isolated aortic valve surgery. Circulation. 2005;112:I448-52.

5. Maganti M, Badiwala M, Sheikh A, Scully H, Feindel C, David TE, et al. Predictors of low cardiac output syndrome after isolated mitral valve surgery. Journal of Thoracic and Cardiovascular Surgery. 2010;140:790-6.

6. Vanky FB, Hakanson E, Tamas E, Svedjeholm R. Risk factors for postoperative heart failure in patients operated on for aortic stenosis. Annals of Thoracic Surgery. 2006;81:1297-304.

7. Vanky FB, Hakanson E, Svedjeholm R. Long-term consequences of postoperative heart failure after surgery for aortic stenosis compared with coronary surgery. Annals of Thoracic Surgery. 2007;83:2036-43.

8. Algarni KD, Maganti M, Yau TM. Predictors of low cardiac output syndrome after isolated coronary artery bypass surgery: trends over 20 years. Annals of Thoracic Surgery. 2011;92:1678-84.

9. Hogue CW, Jr., Sundt T, 3rd, Barzilai B, Schecthman KB, Davila-Roman VG. Cardiac and neurologic complications identify risks for mortality for both men and women undergoing coronary artery bypass graft surgery. Anesthesiology. 2001;95:10748 .

10. Vanky F, Hakanson E, Maros T, Svedjeholm R. Different characteristics of postoperative heart failure after surgery for aortic stenosis and coronary disease. Scandinavian Cardiovascular Journal. 2004;38:152-8.

11. Gillies M, Bellomo R, Doolan L, Buxton B. Bench-to-bedside review: inotropic drug therapy after adult cardiac surgery -- a systematic literature review. Critical Care (London, England). 2005;9:266-79.

12. Fellahi JL, Parienti JJ, Hanouz JL, Plaud B, Riou B, Ouattara A. Perioperative use of dobutamine in cardiac surgery and adverse cardiac outcome: propensity-adjusted analyses. Anesthesiology. 2008;108:979-87.

13. Coronel R, de Groot JR, van Lieshout JJ, Research ObotetoC. Defining heart failure. Cardiovascular Research. 2001;50:419-22.

14. Vanhanen I, Håkanson E, Jorfeldt L, Svedjeholm R. Intravenous aspartate infusion after a coronary operation: effects on myocardial metabolism and hemodynamic state. Annals of Thoracic Surgery. 1998;50:1296-302.

15. Hakanson E, Svedjeholm R, Vanhanen I. Physiologic aspects in postoperative cardiac patients. Annals of Thoracic Surgery. 1995;59:S12-S4.

16. Holm J, Hakanson E, Vanky F, Svedjeholm R. Mixed venous oxygen saturation predicts short- and long-term outcome after coronary artery bypass grafting surgery: a retrospective cohort analysis. British Journal of Anaesthesia. 2011;107:344-50. 
17. Holm J, Hakanson RE, Vanky F, Svedjeholm R. Mixed venous oxygen saturation is a prognostic marker after surgery for aortic stenosis. Acta Anaesthesiologica Scandinavica. 2010;54:589-95.

18. Svedjeholm R, Hakanson E, Szabo Z. Routine SvO2 measurement after CABG surgery with a surgically introduced pulmonary artery catheter. European Journal of Cardio-Thoracic Surgery. 1999; 16:450-7.

19. Lomivorotov VV, Efremov SM, Kirov MY, Fominskiy EV, Karaskov AM. LowCardiac-Output Syndrome After Cardiac Surgery. Journal of Cardiothoracic and Vascular Anesthesia. 2017;31:291-308.

20. Mehta RH, Leimberger JD, van Diepen S, Meza J, Wang A, Jankowich R, et al. Levosimendan in patients with left ventricular dysfunction undergoing cardiac surgery. New England Journal of Medicine. 2017;376:2032-42.

21. Levin ER, Gardner DG, Samson WK. Natriuretic peptides. New England Journal of Medicine. 1998;339:321-8.

22. Sudoh T, Minamino N, Kangawa K, Matsuo H. Brain natriuretic peptide-32: Nterminal six amino acid extended form of brain natriuretic peptide identified in porcine brain. Biochemical and Biophysical Research Communications. 1988;155:726-32.

23. Hunt PJ, Yandle TG, Nicholls MG, Richards AM, Espiner EA. The amino-terminal portion of pro-brain natriuretic peptide (Pro-BNP) circulates in human plasma. Biochemical and Biophysical Research Communications. 1995;214:1175-83.

24. Maeda K, Tsutamoto T, Wada A, Hisanaga T, Kinoshita M. Plasma brain natriuretic peptide as a biochemical marker of high left ventricular end-diastolic pressure in patients with symptomatic left ventricular dysfunction. American Heart Journal. 1998;135:82532 .

25. Liang F, O'Rear J, Schellenberger U, Tai L, Lasecki M, Schreiner GF, et al. Evidence for functional heterogeneity of circulating B-type natriuretic peptide. Journal of the American College of Cardiology. 2007;49:1071-8.

26. Maisel A, Mueller C, Adams K, Jr., Anker SD, Aspromonte N, Cleland JG, et al. State of the art: using natriuretic peptide levels in clinical practice. European Journal of Heart Failure. 2008;10:824-39.

27. Daniels LB, Maisel AS. Natriuretic peptides. Journal of the American College of Cardiology. 2007;50:2357-68.

28. Bergler-Klein J, Gyongyosi M, Maurer G. The role of biomarkers in valvular heart disease: focus on natriuretic peptides. Canadian Journal of Cardiology. 2014;30:1027-34. 29. Pascual-Figal DA, Antolinos MJ, Bayes-Genis A, Casas T, Nicolas F, Valdes M. Btype natriuretic peptide release in the coronary effluent after acute transient ischaemia in humans. Heart. 2007;93:1077-80.

30. Redfield MM, Rodeheffer RJ, Jacobsen SJ, Mahoney DW, Bailey KR, Burnett JC, Jr. Plasma brain natriuretic peptide concentration: impact of age and gender. Journal of the American College of Cardiology. 2002;40:976-82.

31. Lamb EJ, Vickery S, Price CP. Amino-terminal pro-brain natriuretic peptide to diagnose congestive heart failure in patients with impaired kidney function. Journal of the American College of Cardiology. 2006;48:1060-1; author reply 1.

32. Wolff B, Haase D, Lazarus P, Machill K, Graf B, Lestin HG, et al. Severe septic inflammation as a strong stimulus of myocardial NT-pro brain natriuretic peptide release. International Journal of Cardiology. 2007;122:131-6.

33. Snipsoyr MG, Ludvigsen M, Petersen E, Wiggers H, Honore B. A systematic review of biomarkers in the diagnosis of infective endocarditis. International Journal of Cardiology. 2016;202:564-70. 
34. Meirovich YF, Veinot JP, de Bold ML, Haddad H, Davies RA, Masters RG, et al. Relationship between natriuretic peptides and inflammation: proteomic evidence obtained during acute cellular cardiac allograft rejection in humans. Journal of Heart and Lung Transplantation. 2008;27:31-7.

35. Swedberg K, Cleland J, Dargie H, Drexler H, Follath F, Komajda M, et al. Guidelines for the diagnosis and treatment of chronic heart failure: executive summary (update 2005): The Task Force for the Diagnosis and Treatment of Chronic Heart Failure of the European Society of Cardiology. European Heart Journal. 2005;26:1115-40.

36. Januzzi JL, Camargo CA, Anwaruddin S, Baggish AL, Chen AA, Krauser DG, et al. The N-terminal pro-BNP investigation of dyspnea in the emergency department (PRIDE) study. American Journal of Cardiology. 2005;95:948-54.

37. Roberts E, Ludman AJ, Dworzynski K, Al-Mohammad A, Cowie MR, McMurray $\mathrm{JJ}$, et al. The diagnostic accuracy of the natriuretic peptides in heart failure: systematic review and diagnostic meta-analysis in the acute care setting. BMJ. 2015;350:h910.

38. Januzzi JL, van Kimmenade R, Lainchbury J, Bayes-Genis A, Ordonez-Llanos J, Santalo-Bel M, et al. NT-proBNP testing for diagnosis and short-term prognosis in acute destabilized heart failure: an international pooled analysis of 1256 patients. European Heart Journal. 2006;27:330-7.

39. Olsson LG, Swedberg K, Cleland JG, Spark PA, Komajda M, Metra M, et al. Prognostic importance of plasma NT-pro BNP in chronic heart failure in patients treated with a beta-blocker: results from the Carvedilol Or Metoprolol European Trial (COMET) trial. European Journal of Heart Failure. 2007;9:795-801.

40. Lee SC, Stevens TL, Sandberg SM, Heublein DM, Nelson SM, Jougasaki M, et al. The potential of brain natriuretic peptide as a biomarker for New York Heart Association class during the outpatient treatment of heart failure. Journal of Cardiac Failure. 2002;8:149-54.

41. Karlstrom P, Alehagen U, Boman K, Dahlstrom U, group UP-s. Brain natriuretic peptide-guided treatment does not improve morbidity and mortality in extensively treated patients with chronic heart failure: responders to treatment have a significantly better outcome. European Journal of Heart Failure. 2011;13:1096-103.

42. Ponikowski P, Voors AA, Anker SD, Bueno H, Cleland JG, Coats AJ, et al. 2016 ESC guidelines for the diagnosis and treatment of acute and chronic heart failure: the task force for the diagnosis and treatment of acute and chronic heart failure of the European Society of Cardiology (ESC). Developed with the special contribution of the Heart Failure Association (HFA) of the ESC. European Journal of Heart Failure. 2016;18:891-975.

43. Yancy CW, Jessup M, Bozkurt B, Butler J, Casey DE, Jr., Colvin MM, et al. 2017 ACC/AHA/HFSA focused update of the 2013 ACCF/AHA guideline for the management of heart failure: a report of the American College of Cardiology/American Heart Association task force on clinical practice guidelines and the Heart Failure Society of America. Journal of Cardiac Failure. 2017;23:628-51.

44. Fellahi JL, Daccache G, Makroum Y, Massetti M, Gerard JL, Hanouz JL. The prognostic value of B-type natriuretic peptide after cardiac surgery: a comparative study between coronary artery bypass graft surgery and aortic valve replacement. Journal of Cardiothoracic and Vascular Anesthesia. 2012;26:624-30.

45. Jogia PM, Kalkoff M, Sleigh JW, Bertinelli A, La Pine M, Richards AM, et al. NTpro BNP secretion and clinical endpoints in cardiac surgery intensive care patients. Anaesthesia and Intensive Care. 2007;35:363-9.

46. Berendes E, Schmidt C, Van Aken H, Hartlage MG, Rothenburger M, Wirtz S, et al. A-type and B-type natriuretic peptides in cardiac surgical procedures. Anesthesia and Analgesia. 2004;98:11-9. 
47. Chenevier-Gobeaux C, Claessens YE, Voyer S, Desmoulins D, Ekindjian OG. Influence of renal function on N-terminal pro-brain natriuretic peptide (NT-proBNP) in patients admitted for dyspnoea in the Emergency Department: comparison with brain natriuretic peptide (BNP). Clinica Chimica Acta. 2005;361:167-75.

48. Jo YY, Kwak YL, Lee J, Choi YS. Relationship between N-terminal pro-B-type natriuretic peptide and renal function: the effects on predicting early outcome after offpump coronary artery bypass surgery. Korean Journal of Anesthesiology. 2011;61:35-41. 49. Wang TJ, Larson MG, Levy D, Benjamin EJ, Leip EP, Wilson PW, et al. Impact of obesity on plasma natriuretic peptide levels. Circulation. 2004;109:594-600.

50. Wirth J, Buijsse B, di Giuseppe R, Fritsche A, Hense HW, Westphal S, et al. Relationship between N-terminal pro-brain natriuretic peptide, obesity and the risk of heart failure in middle-aged German adults. PloS One. 2014;9:e113710.

51. Kerbaul F, Collart F, Giorgi R, Oddoze C, Lejeune PJ, Guidon C, et al. Increased plasma levels of pro-brain natriuretic peptide in patients with cardiovascular complications following off-pump coronary artery surgery. Intensive Care Medicine. 2004;30:1799-806.

52. Bergler-Klein J, Klaar U, Heger M, Rosenhek R, Mundigler G, Gabriel H, et al. Natriuretic peptides predict symptom-free survival and postoperative outcome in severe aortic stenosis. Circulation. 2004;109:2302-8.

53. Cuthbertson BH, McKeown A, Croal BL, Mutch WJ, Hillis GS. Utility of B-type natriuretic peptide in predicting the level of peri- and postoperative cardiovascular support required after coronary artery bypass grafting. Critical Care Medicine. 2005;33:437-42.

54. Eliasdottir SB, Klemenzson G, Torfason B, Valsson F. Brain natriuretic peptide is a good predictor for outcome in cardiac surgery. Acta Anaesthesiologica Scandinavica. 2008;52:182-7.

55. Fox AA, Shernan SK, Collard CD, Liu KY, Aranki SF, DeSantis SM, et al. Preoperative B-type natriuretic peptide is as independent predictor of ventricular dysfunction and mortality after primary coronary artery bypass grafting. Journal of Thoracic and Cardiovascular Surgery. 2008;136:452-61.

56. Pedrazzini GB, Masson S, Latini R, Klersy C, Rossi MG, Pasotti E, et al. Comparison of brain natriuretic peptide plasma levels versus logistic EuroSCORE in predicting inhospital and late postoperative mortality in patients undergoing aortic valve replacement for symptomatic aortic stenosis. American Journal of Cardiology. 2008;102:749-54.

57. Turk T, Ata Y, Ay D, Ozkan H, Vural H, Yavuz S, et al. Plasma brain natriuretic Peptide after isolated on-pump coronary artery bypass grafting: prediction of postoperative adverse outcomes. Heart Surgery Forum. 2008;11:E84-9.

58. Attaran S, Sherwood R, Desai J, Langworthy R, Mhandu P, John L, et al. Brain natriuretic peptide a predictive marker in cardiac surgery. Interactive Cardiovascular and Thoracic Surgery. 2009;9:662-6.

59. Cuthbertson BH, Croal BL, Rae D, Gibson PH, McNeilly JD, Jeffrey RR, et al. Nterminal pro-B-type natriuretic peptide levels and early outcome after cardiac surgery: a prospective cohort study. British Journal of Anaesthesia. 2009;103:647-53.

60. Wang Z, Liang D, Fu Q, Jia L, Men J, Wei M. Perioperative brain natriuretic peptide in off-pump coronary artery bypass. Acta Cardiologica. 2010;65:297-301.

61. Schachner T, Wiedemann D, Fetz H, Laufer G, Kocher A, Bonaros N. Influence of preoperative serum $\mathrm{N}$-terminal pro-brain type natriuretic peptide on the postoperative outcome and survival rates of coronary artery bypass patients. Clinics. 2010;65:1239-45. 62. Fellahi JL, Daccache G, Rubes D, Massetti M, Gerard JL, Hanouz JL. Does preoperative B-type natriuretic peptide better predict adverse outcome and prolonged 
length of stay than the standard European System for Cardiac Operative Risk Evaluation after cardiac surgery? Journal of Cardiothoracic and Vascular Anesthesia. 2011;25:25662.

63. Hernandez-Leiva E, Dennis R, Isaza D, Umana JP. Hemoglobin and B-type natriuretic peptide preoperative values but not inflammatory markers, are associated with postoperative morbidity in cardiac surgery: a prospective cohort analytic study. Journal of Cardiothoracic Surgery. 2013;8:170.

64. Singh S, Kapoor A, Agarwal SK, Pande S, Sinha A, Rai H. Differential Release Kinetics of Cardiac Biomarkers in Patients Undergoing Valve Replacement Surgery. Journal of Cardiac Surgery. 2014;29:134-40.

65. Holm J, Vidlund M, Vanky F, Friberg O, Hakanson E, Svedjeholm R. Preoperative NT-proBNP independently predicts outcome in patients with acute coronary syndrome undergoing CABG. Scandinavian Cardiovascular Journal. 2013;47:28-35.

66. Holm J, Vidlund M, Vanky F, Friberg O, Hakanson E, Walther S, et al. EuroSCORE II and N-terminal pro-B-type natriuretic peptide for risk evaluation: an observational longitudinal study in patients undergoing coronary artery bypass graft surgery. British Journal of Anaesthesia. 2014;113:75-82.

67. Cuthbertson BH, Croal BL, Rae D, Harrild K, Gibson PH, Prescott GJ, et al. Nterminal pro-B-type natriuretic peptide concentrations and long-term outcome after cardiac surgery: a prospective cohort study. British Journal of Anaesthesia. 2013;110:214-21.

68. Fox AA, Nascimben L, Body SC, Collard CD, Mitani AA, Liu KY, et al. Increased perioperative $b$-type natriuretic peptide associates with heart failure hospitalization or heart failure death after coronary artery bypass graft surgery. Anesthesiology. 2013;119:284-94.

69. Cantinotti M, Giordano R, Scalese M, Molinaro S, Della Pina F, Storti S, et al. Prognostic role of BNP in children undergoing surgery for congenital heart disease: analysis of prediction models incorporating standard risk factors. Clinical Chemistry and Laboratory Medicine. 2015;53:1839-46.

70. Nashef SA, Roques F, Sharples LD, Nilsson J, Smith C, Goldstone AR, et al. EuroSCORE II. European Journal of Cardio-Thoracic Surgery. 2012;41:734-44; discussion 44-5.

71. Reyes G, Fores G, Rodriguez-Abella RH, Cuerpo G, Vallejo JL, Romero C, et al. NT-proBNP in cardiac surgery: a new tool for the management of our patients? Interactive Cardiovascular and Thoracic Surgery. 2005;4:242-7.

72. Cai B, Wang L, Liu J, Shi Y, Guo Y. N-terminal pro-Brain natriuretic peptide as a useful biomarker for monitoring prognosis in patients with cardiac valve replacement. Journal of Clinical Laboratory Analysis. 2011;25:149-55.

73. Crescenzi G, Landoni G, Bignami E, Belloni I, Biselli C, Rosica C, et al. N-terminal B-natriuretic peptide after coronary artery bypass graft surgery. Journal of Cardiothoracic and Vascular Anesthesia. 2009;23:147-50.

74. Young YR, Sheu BF, Li WC, Hsieh TM, Hung CW, Chang SS, et al. Predictive value of plasma brain natriuretic peptide for postoperative cardiac complications--a systemic review and meta-analysis. Journal of Critical Care. 2014;29:696 e1-10.

75. Suttner S, Boldt J, Lang K, Rohm KD, Piper SN, Mayer J. Association of N-terminal pro-brain natriuretic peptide and cardiac troponin $\mathrm{T}$ with in-hospital cardiac events in elderly patients undergoing coronary artery surgery. European Journal of Anaesthesiology. 2008;25:834-41.

76. Provenchere S, Berroeta C, Reynaud C, Baron G, Poirier I, Desmonts JM, et al. Plasma brain natriuretic peptide and cardiac troponin I concentrations after adult cardiac 
surgery: association with postoperative cardiac dysfunction and 1-year mortality. Critical Care Medicine. 2006;34:995-1000.

77. Nozohoor S, Nilsson J, Algotsson L, Sjogren J. Postoperative increase in B-type natriuretic peptide levels predicts adverse outcome after cardiac surgery. Journal of Cardiothoracic and Vascular Anesthesia. 2011;25:469-75.

78. Singh S, Kapoor A, Agarwal SK, Pande S, Sinha A, Rai H, et al. Differential release kinetics of cardiac biomarkers in off-pump coronary bypass. Asian Cardiovascular \& Thoracic Annals. 2014;22:674-81.

79. Hutfless R, Kazanegra R, Madani M, Bhalla MA, Tulua-Tata A, Chen A, et al. Utility of B-type natriuretic peptide in predicting postoperative complications and outcomes in patients undergoing heart surgery. Journal of the American College of Cardiology. 2004;43:1873-9.

80. Fellahi JL, Hanouz JL, Le Manach Y, Gue X, Monier E, Guillou L, et al. Simultaneous measurement of cardiac troponin I, B-type natriuretic peptide, and Creactive protein for the prediction of long-term cardiac outcome after cardiac surgery. Anesthesiology. 2009;111:250-7.

81. Lurati Buse GA, Bolliger D, Seeberger E, Kasper J, Grapow M, Koller MT, et al. Troponin $\mathrm{T}$ and B-type natriuretic peptide after on-pump cardiac surgery: prognostic impact on 12-month mortality and major cardiac events after adjustment for postoperative complications. Circulation. 2014;130:948-57.

82. Bastien O, Vallet B, French Study Group A. French multicentre survey on the use of inotropes after cardiac surgery. Critical Care (London, England). 2005;9:241-2.

83. Mebazaa A, Pitsis AA, Rudiger A, Toller W, Longrois D, Ricksten SE, et al. Clinical review: practical recommendations on the management of perioperative heart failure in cardiac surgery. Critical Care (London, England). 2010;14:201.

84. Lazar HL, Buckberg GD, Foglia RP, Manganaro AJ, Maloney JV, Jr. Detrimental effects of premature use of inotropic drugs to discontinue cardiopulmonary bypass. Journal of Thoracic and Cardiovascular Surgery. 1981;82:18-25.

85. Evans JS, Huang SJ, McLean AS, Nalos M. Left ventricular outflow tract obstruction-be prepared! Anaesthesia and Intensive Care. 2017;45:12-20.

86. Rastan AJ, Dege A, Mohr M, Doll N, Falk V, Walther T, et al. Early and late outcomes of 517 consecutive adult patients treated with extracorporeal membrane oxygenation for refractory postcardiotomy cardiogenic shock. Journal of Thoracic and Cardiovascular Surgery. 2010;139:302-11, 11 e1.

87. Schutze GE, Heulitt MJ. Infections during extracorporeal life support. Journal of Pediatric Surgery. 1995;30:809-12.

88. Schipke JD, Friebe R, Gams E. Forty years of glucose-insulin-potassium (GIK) in cardiac surgery: a review of randomized, controlled trials. European Journal of CardioThoracic Surgery. 2006;29:479-85.

89. Rau EE, Shine KI, Gervais A, Douglas AM, Amos EC, 3rd. Enhanced mechanical recovery of anoxic and ischemic myocardium by amino acid perfusion. American Journal of Physiology. 1979;236:H873-9.

90. Pisarenko OI. Mechanisms of myocardial protection by amino acids: facts and hypotheses. Clinical and Experimental Pharmacology and Physiology. 1996;23:627-33.

91. Lazar HL, Buckberg GD, Manganaro AJ, Becker H, Maloney JV, Jr. Reversal of ischemic damage with amino acid substrate enhancement during reperfusion. Surgery. 1980;88:702-9.

92. Svedjeholm R, Hakanson E, Vanhanen I. Rationale for metabolic support with amino acids and glucose-insulin-potassium (GIK) in cardiac surgery. Annals of Thoracic Surgery. 1995;59:S15-22. 
93. Mudge GH, Jr., Mills RM, Jr., Taegtmeyer H, Gorlin R, Lesch M. Alterations of myocardial amino acid metabolism in chronic ischemic heart disease. Journal of Clinical Investigation. 1976;58:1185-92.

94. Thomassen AR, Nielsen TT, Bagger JP, Henningsen P. Myocardial exchanges of glutamate, alanine and citrate in controls and patients with coronary artery disease. Clinical Science (London, England: 1979). 1983;64:33-40.

95. Svedjeholm R, Ekroth R, Joachimsson PO, Ronquist G, Svensson S, Tyden H. Myocardial uptake of amino acids and other substrates in relation to myocardial oxygen consumption four hours after cardiac operations. Journal of Thoracic and Cardiovascular Surgery. 1991;101:688-94.

96. Thomassen A, Nielsen TT, Bagger JP. Alterations in myocardial uptake of glutamate and release of alanine after propranolol, nifedipine, and glyceryl trinitrate in coronary artery disease. Journal of Cardiovascular Pharmacology. 1985;7:394-400.

97. Thomassen AR, Mortensen PT, Nielsen TT, Falstie-Jensen N, Thygesen K, Henningsen P. Altered plasma concentrations of glutamate, alanine and citrate in the early phase of acute myocardial infarction in man. European Heart Journal. 1986;7:773-8.

98. Thomassen A, Nielsen TT, Bagger JP, Pedersen AK, Henningsen P. Antiischemic and metabolic effects of glutamate during pacing in patients with stable angina pectoris secondary to either coronary artery disease or syndrome X. American Journal of Cardiology. 1991;68:291-5.

99. Pisarenko OI, Portnoy VF, Studneva IM, Arapov AD, Korostylev AN. Glutamateblood cardioplegia improves ATP preservation in human myocardium. Biomedica Biochimica Acta. 1987;46:499-504.

100. Svedjeholm R, Vanhanen I, Hakanson E, Joachimsson PO, Jorfeldt L, Nilsson L. Metabolic and hemodynamic effects of intravenous glutamate infusion early after coronary operations. Journal of Thoracic and Cardiovascular Surgery. 1996;112:1468-77. 101. Pisarenko OI, Lepilin MG, Ivanov VE. Cardiac metabolism and performance during L-glutamic acid infusion in postoperative cardiac failure. Clinical Science (London, England: 1979). 1986;70:7-12.

102. Vidlund M, Hakanson E, Friberg O, Juhl-Andersen S, Holm J, Vanky F, et al. GLUTAMICS--a randomized clinical trial on glutamate infusion in 861 patients undergoing surgery for acute coronary syndrome. Journal of Thoracic and Cardiovascular Surgery. 2012;144:922-30 e7.

103. Hultkvist H, Holm J, Svedjeholm R, Vanky F. Rise and fall of NT-proBNP in aortic valve intervention. Open Heart. 2018;5:e000739.

104. Vahanian A, Alfieri O, Andreotti F, Antunes MJ, Baron-Esquivias G, Baumgartner $\mathrm{H}$, et al. Guidelines on the management of valvular heart disease (version 2012): the joint task force on the management of valvular heart disease of the European Society of Cardiology (ESC) and the European Association for Cardio-Thoracic Surgery (EACTS). European Journal of Cardio-Thoracic Surgery. 2012;42:S1-44.

105. Kolh P, Windecker S, Alfonso F, Collet JP, Cremer J, Falk V, et al. 2014 ESC/EACTS guidelines on myocardial revascularization: the task force on myocardial revascularization of the European Society of Cardiology (ESC) and the European Association for Cardio-Thoracic Surgery (EACTS). Developed with the special contribution of the European Association of Percutaneous Cardiovascular Interventions (EAPCI). European Journal of Cardio-Thoracic Surgery. 2014;46:517-92.

106. Surgenor SD, O'Connor GT, Lahey SJ, Quinn R, Charlesworth DC, Dacey LJ, et al. Predicting the risk of death from heart failure after coronary artery bypass graft surgery. Anesthesia and Analgesia. 2001;92:596-601. 
107. Butterworth JFt, Legault C, Royster RL, Hammon JW, Jr. Factors that predict the use of positive inotropic drug support after cardiac valve surgery. Anesthesia and Analgesia. 1998;86:461-7.

108. Georges A, Forestier F, Valli N, Plogin A, Janvier G, Bordenave L. Changes in type $\mathrm{B}$ natriuretic peptide (BNP) concentrations during cardiac valve replacement. European Journal of Cardio-Thoracic Surgery. 2004;25:941-5.

109. Vikholm P, Schiller P, Hellgren L. Preoperative brain natriuretic peptide predicts late mortality and functional class but not hospital readmission after cardiac surgery. Journal of Cardiothoracic and Vascular Anesthesia. 2014;28:520-7.

110. Fox AA. Perioperative B-type natriuretic peptide/N-terminal pro-B-type natriuretic peptide: next steps to clinical practice. Anesthesiology. 2015;123:246-8.

111. Clerico A, Giannoni A, Vittorini S, Emdin M. The paradox of low BNP levels in obesity. Heart Failure Reviews. 2012;17:81-96.

112. Ndrepepa G, Braun S, Mehilli J, von Beckerath N, Vogt W, Schomig A, et al. Plasma levels of N-terminal pro-brain natriuretic peptide in patients with coronary artery disease and relation to clinical presentation, angiographic severity, and left ventricular ejection fraction. American Journal of Cardiology. 2005;95:553-7.

113. Palazzuoli A, Caputo M, Fineschi M, Navarri R, Calabro A, Cameli M, et al. B-type natriuretic peptide as an independent predictor of coronary disease extension in non-ST elevation coronary syndromes with preserved systolic function. Eur J Prev Cardiol. 2012;19:366-73.

114. Omland T, Sabatine MS, Jablonski KA, Rice MM, Hsia J, Wergeland R, et al. Prognostic value of B-Type natriuretic peptides in patients with stable coronary artery disease: the PEACE Trial. Journal of the American College of Cardiology. 2007;50:20514.

115. Magne J, Mahjoub H, Pierard LA, O'Connor K, Pirlet C, Pibarot P, et al. Prognostic importance of brain natriuretic peptide and left ventricular longitudinal function in asymptomatic degenerative mitral regurgitation. Heart. 2012;98:584-91.

116. Marechaux S, Hattabi M, Juthier F, Neicu DV, Richardson M, Carpentier E, et al. Clinical and echocardiographic correlates of plasma B-type natriuretic peptide levels in patients with aortic valve stenosis and normal left ventricular ejection fraction. Echocardiography. 2011;28:695-702.

117. Weber M, Hausen M, Arnold R, Nef H, Moellman H, Berkowitsch A, et al. Prognostic value of $\mathrm{N}$-terminal pro-B-type natriuretic peptide for conservatively and surgically treated patients with aortic valve stenosis. Heart. 2006;92:1639-44.

118. Kampaktsis PN, Kokkinidis DG, Wong SC, Vavuranakis M, Skubas NJ, Devereux RB. The role and clinical implications of diastolic dysfunction in aortic stenosis. Heart. 2017;103:1481-7.

119. Mauermann E, Bolliger D, Fassl J, Grapow M, Seeberger EE, Seeberger MD, et al. Absolute Postoperative B-Type Natriuretic Peptide Concentrations, but Not Their General Trend, Are Associated With 12-Month, All-Cause Mortality After On-Pump Cardiac Surgery. Anesthesia and Analgesia. 2017;125:753-61.

120. Vidlund M, Tajik B, Hakanson E, Friberg O, Holm J, Vanky F, et al. Post hoc analysis of the glutamics-trial: intravenous glutamate infusion and use of inotropic drugs after cabg. BMC Anesthesiology. 2016;16:54.

121. Langenberg CJ, Pietersen HG, Geskes G, Wagenmakers AJ, Lange SD, Schouten $\mathrm{HJ}$, et al. The effect of glutamate infusion on cardiac performance is independent of changes in metabolism in patients undergoing routine coronary artery bypass surgery. Clinical Science (London, England: 1979). 2001;101:573-80. 
122. Hultkvist H, Vanky F, Svedjeholm R. The combined impact of postoperative heart failure and EuroSCORE on long-term outcome after surgery for aortic stenosis. Journal of Heart Valve Disease. 2011;20:633-8.

123. Svedjeholm R, Vidlund M, Vanhanen I, Hakanson E. A metabolic protective strategy could improve long-term survival in patients with LV-dysfunction undergoing CABG. Scandinavian Cardiovascular Journal. 2010;44:45-58. 


\section{Papers}

The papers associated with this thesis have been removed for copyright reasons. For more details about these see:

http://urn.kb.se/resolve?urn=urn:nbn:se:liu:diva-161324 


\section{FACULTY OF MEDICINE AND HEALTH SCIENCES}

Linköping University Medical Dissertation No. 1712, 2019

Department of Medical and Health Sciences

Linköping University

SE-581 83 Linköping, Sweden

www.liu.se 